University of Wollongong

Research Online

Faculty of Engineering and Information

Faculty of Engineering and Information

Sciences - Papers: Part B

Sciences

2020

Solar medium-low temperature thermal utilization and effect analysis of boundary condition: A tutorial

Yu Bie

Zhixiong $\mathrm{Li}$

University of Wollongong, lizhixio@uow.edu.au

Jilin Lei

Zhenjun Ma

University of Wollongong, zhenjun@uow.edu.au

Ming Li

See next page for additional authors

Follow this and additional works at: https://ro.uow.edu.au/eispapers1

Part of the Engineering Commons, and the Science and Technology Studies Commons

Research Online is the open access institutional repository for the University of Wollongong. For further information contact the UOW Library: research-pubs@uow.edu.au 


\title{
Solar medium-low temperature thermal utilization and effect analysis of boundary condition: A tutorial
}

\author{
Abstract \\ (c) 2020 International Solar Energy Society Solar thermal utilization is an important part of renewable \\ energy applications, and its development and application have received extensive attention. Based on the \\ development status of medium and low temperature solar thermal utilization systems, this paper first \\ introduces the application and performance research on subsystems of the solar system including heat \\ collection, heat storage and heat utilization units. It then introduces the theoretical and experimental \\ development of matching relationships and dynamic performance of the medium and low temperature \\ thermal utilization systems. Lastly, a case study analysis of a solar thermal system performance was \\ carried out under different thermal boundary conditions. The influence of the boundary conditions of the \\ heat storage system and the actual weather conditions on its performance is explored. The results \\ showed that the boundary conditions of constant temperature and the boundary conditions of constant \\ heat flow density have their own advantages. The heat source conditions provided by heat transfer \\ medium are similar to the constant heat flux boundary condition. The work of this paper provided a \\ theoretical basis for the subsequent application and performance study of solar medium and low \\ temperature thermal utilization systems.

\section{Disciplines} \\ Engineering | Science and Technology Studies

\section{Publication Details} \\ Bie, Y., Li, Z., Lei, J., Ma, Z., Li, M., Krolczyk, G. \& Li, W. (2020). Solar medium-low temperature thermal \\ utilization and effect analysis of boundary condition: A tutorial. Solar Energy, 197 238-253.
}

\section{Authors}

Yu Bie, Zhixiong Li, Jilin Lei, Zhenjun Ma, Ming Li, Grzegorz Krolczyk, and Weihua Li 
Solar Medium-low Temperature Thermal Utilization and Effect Analysis of Boundary

\title{
Condition: A Tutorial
}

\author{
Yu Bie ${ }^{1,2}$, Zhixiong Lij ${ }^{3 *}$, Jilin Lei ${ }^{1}$, Zhenjun $\mathrm{Ma}^{4}$, Ming Li ${ }^{5}$, Grzegorz Królczyk ${ }^{6}$, Weihua $\mathrm{Li}^{3}$ \\ 1. Yunnan Province Key Laboratory of Internal Combustion Engines, Kunming University of Science and \\ Technology, Kunming 650500, PR China \\ 2. Faculty of Chemical Engineering, Kunming University of Science and Technology, Kunming 650500, PR \\ China \\ 3. School of Mechanical, Materials, Mechatronic and Biomedical Engineering, University of Wollongong, \\ Wollongong, 2522, Australia \\ 4. Sustainable Buildings Research Centre, University of Wollongong, 2522, Australia \\ 5. Solar Energy Research Institute, Yunnan Normal University, Kunming 650500, China \\ 6. Department of Manufacturing Engineering and Automation Products, Opole University of Technology, Opole \\ 45758, Poland \\ *Corresponding author: zhixiong_li@uow.edu.au
}

\begin{abstract}
Solar thermal utilization is an important part of renewable energy applications, and its development and application have received extensive attention. Based on the development status of medium and low temperature solar thermal utilization systems, this paper first introduces the application and performance research on subsystems of the solar system including heat collection, heat storage and heat utilization units. It then introduces the theoretical and experimental development of matching relationships and dynamic performance of the medium and low temperature thermal utilization systems. Lastly, a case study analysis of a solar thermal system performance was carried out under different thermal boundary conditions. The influence of the boundary conditions of the heat storage system and the actual weather conditions on its performance is explored. The results showed that the boundary conditions of constant temperature and the boundary conditions of constant heat flow density have their own advantages. The heat source conditions provided by heat transfer medium are similar to the constant heat flux boundary condition. The work of this paper provided a theoretical basis for the subsequent application and performance study of solar medium and low temperature thermal utilization systems.
\end{abstract}

Key words: medium-low temperature thermal utilization; solar heat for industrial processes; solar heat collection system; heat storage system; thermal boundary condition

\section{Introduction}

With the increasingly sharp energy competition around the world, the development of renewable energy is regarded as the core task of the Fourth Scientific and Technological Revolution, which can promote the transformation of world energy structure and even economic structure. According to the '2018 BP Statistical Review of World Energy [1], the world energy market continued to transition to a low-carbon economy in 2017, and the electricity generation capacity of renewable energy increased by $17 \%$. This is the largest increase on record, among which solar energy contributed one third of this increase. The policy support and low cost of solar power (5 cents per kilowatt hour) help worldwide solar capacity grow by 100 gigawatts. China remains the world's largest energy consumer, accounting for $23.2 \%$ of global energy consumption and $33.6 \%$ of the growth in global energy consumption. Among non-fossil energy sources, solar energy 
consumption in China was ranked as the fastest growing (76\%). In addition to the explosive growth of solar photovoltaic power generation, the installed capacity of solar thermal power generation will also reach to $5 \mathrm{GW}$ during the period of the $13^{\text {th }}$ Five-year Plan proposed by the Chinese government [2].

As solar thermal power generation technology becomes increasingly mature and widespread, the application potential of concentrated solar thermal utilization in other fields, however, is still rarely explored, especially in the field of industrial processes [3]. The total amount of industrial thermal load is huge, which consumed at least $15 \%$ to $30 \%$ of the total social energy consumption in most industrialized countries around the world $[4,5]$. Taking China as an example, the total energy consumed by industrial production currently accounts for $60-70 \%$ of the total energy consumption of the whole country. The proportion was $70.4 \%$ in 2017 , of which $50-70 \%$ was used for industrial processing heating, presenting a substantial energy saving potential [6]. The proportion of terminal energy consumption in different regions is shown in Figure 1 [7].

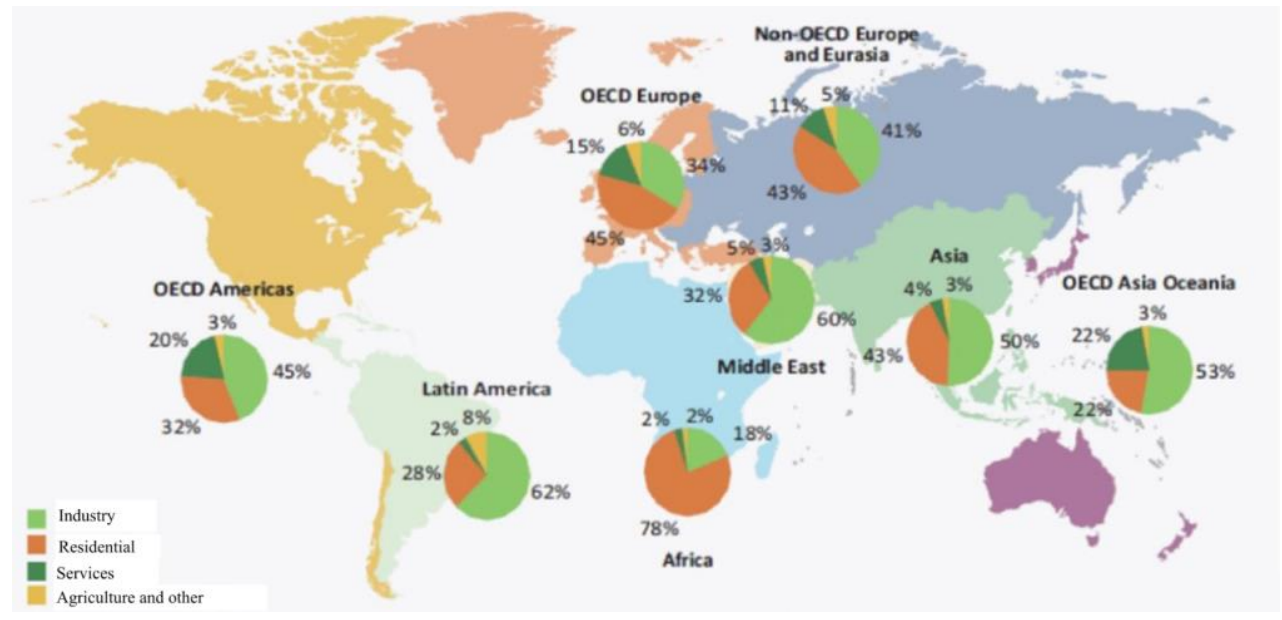

Fig. 1. Share of the total final energy consumption by region [3].

Currently, the heat load of most industrial process is generally less than $250^{\circ} \mathrm{C}$, with pressure under $8 \mathrm{~atm}$. For example, a significant amount of heat is required in the process of the silk of tobacco industry under the temperature of $150-200{ }^{\circ} \mathrm{C}$, drying and heating Chinese herbal medicine or tea products under the temperature of $60-90{ }^{\circ} \mathrm{C}$, and de-enzyme process for Puer tea under the temperature of about $180^{\circ} \mathrm{C}$. Previous studies have shown that the solar energy could be very suitable for heating the carrier to the temperature below $250{ }^{\circ} \mathrm{C}$, therefore, as a potential alternative of fossil energy, solar energy can form a tendency of solar heat for industrial processes (SHIP) [8]. Currently SHIP is in its early stages of development and is seen as the most promising direction for solar thermal utilization in India [9] and in Australia [10]. By the end of 2017, the number of the process thermal systems in the global solar energy industry reached 283, and the installed capacity in 2015 reached 100 MWth. The collector area and investment of the newly added SHIP projects in the last five years are shown in Figure 2. We can see that the newly added heat collector area was the largest in 2017, while the investment cost decreased, indicating that the cost of the system kept falling along with the technological development. The projects were mainly distributed in Mexico (66 projects), India (46 projects), Australia (26 projects) and Germany (26 projects) [11]. In addition to the power generation, the projects in the major developing countries [9] and developed countries 
$[5,10]$ were mainly applied in the areas of food processing $[12,15]$, textile $[12,14]$, air-conditioning [13], agricultural and forestry products drying [16], and chemical synthesis and process [17]. However, solar heat for industrial processes in China is growing much slower [7]. The statistical data for the global SHIP map (see Figure 3) shows that the global SHIP utilization is mainly concentrated in the northern hemisphere and low-latitude regions [18].

Solar thermal utilization can be divided into low-temperature thermal utilization (below $80^{\circ} \mathrm{C}$ ), medium-temperature thermal utilization $\left(80-250{ }^{\circ} \mathrm{C}\right)$ and high-temperature thermal utilization (above $250^{\circ} \mathrm{C}$ ). The low-temperature thermal utilization is relatively mature, and it is also the most widely used form of application in, such as the solar heating systems [19]. The medium- and hightemperature thermal utilizations require concentrating light devices to achieve a relatively high temperature, and these devices are mainly used in solar concentrating thermal power generation [20]. Processes at low and medium temperatures have a high share of heat demand in the field of light industry [21] such as food \& beverage, tobacco, pulp \& paper, and also in some heave industries [22] such as machinery, mining, and transport equipment manufacturing, as shown in Table 1 [23]. In recent years, the SHIP has been regarded to be one of the most potential fields for solar thermal application [24]. 283 operating solar thermal projects for process heat have been reported worldwide, with a total capacity of about $88 \mathrm{MWth}\left(125,000 \mathrm{~m}^{2}\right)$ [11]. The International Energy Agency Solar Heating and Cooling (IEA SHC) Task 49 specially focuses on the solar heat integration in industrial processes, which includes three subtasks: a) process optimization, integration and intensification; b) design guidelines, case studies and dissemination; and c) process heat collector development and testing [25]. This cooperation program provides technical support and popularization for the SHIP systems.
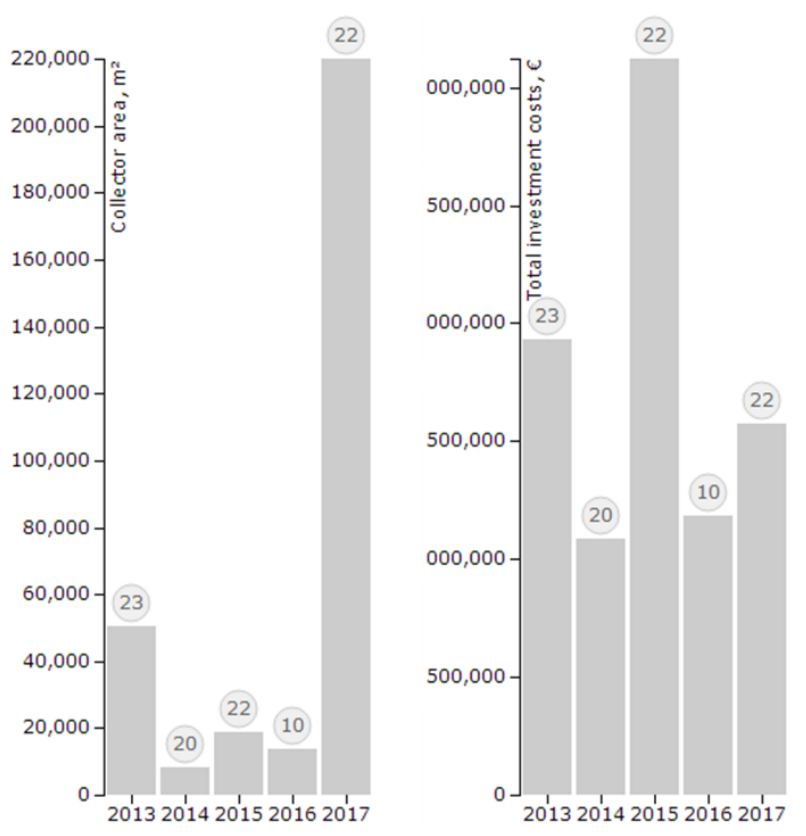

Fig. 2. The global collectors area and investment costs for SHIP systems [11] (The figures in the circle stand for the number of SHIP projects in operation).

The production processes of cleaning and disinfecting cans, kegs and bottles require hot water above $60{ }^{\circ} \mathrm{C}$ and low-pressure hot steam above $100^{\circ} \mathrm{C}$. Therefore, cascaded utilization of energy 
can be realized, which can preheat boiler feed water and produce steam. The common combinations of SHIP and process technology are to provide direct heat source for process equipment, and to preheat devices such as steam boilers and heating system with indirect heat transfer of heat storage devices $[7,26]$.

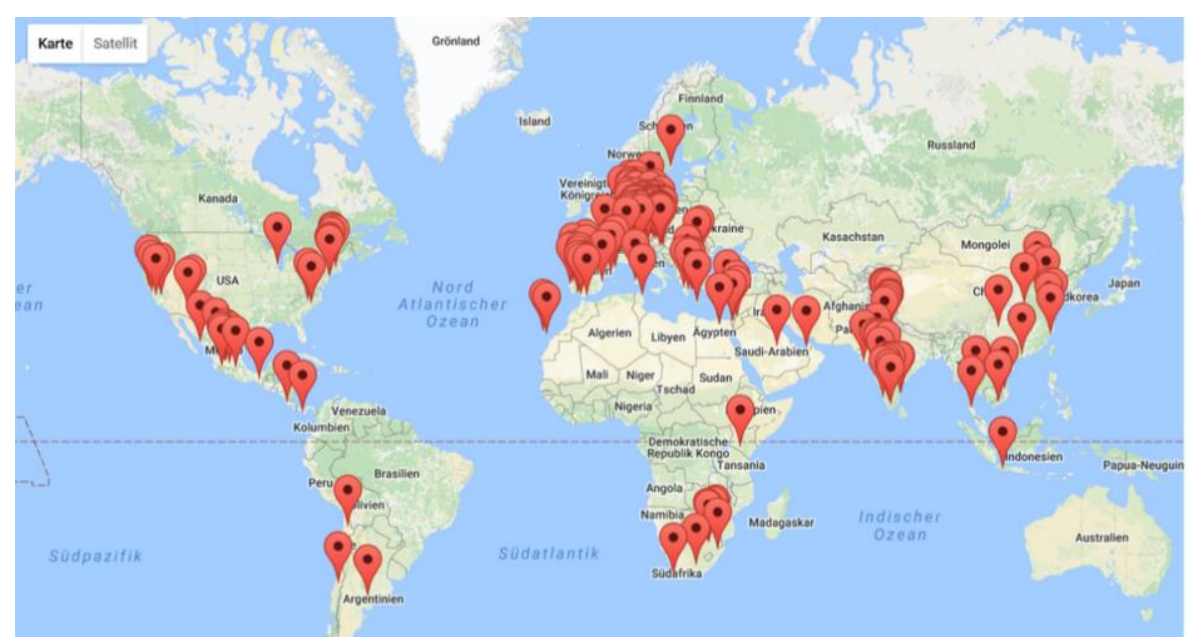

Fig. 3. Map of the globally statistical SHIP applications [18].

Although the SHIP has a great potential for decreasing the fuel consumption, there are also some barriers existed to prevent the development of large-scale SHIP systems. In fact, several SHIP systems have been integrated into the production process. The actual capacity installed so far is relatively small even though a very large potential of harnessing solar energy for meeting the process heating demand in industries has been reported [27]. Several reasons are summarized here includes: it is difficult to integrate solar energy systems with existing or optimized heat flow processes; industrial production systems above the scale are much smaller than small-scale systems, and the latter requires customized solutions; the cost of the fixed asset needs to be paid in advance [27]; the lack of adequately competent designers and design software [28]; the lack of a simple heat storage device [29]; and the lack of adequate policy and regulatory support compared to photovoltaic and concentrated solar thermal (CSP) systems [30]. For low-concentration (solar concentrating ratio below 10) SHIP with the operating temperature range of $60^{\circ} \mathrm{C}-250{ }^{\circ} \mathrm{C}$, the application is much less in explored comparison to qthe low-temperature thermal system, and the degree of attention is not as good as that of solar thermal power generation. The core problems that need to be solved are mainly reflected in two aspects: 1) insufficient market competitiveness resulted from low energy flow density of solar radiation, low economic efficiency of low-concentration light, and short operating life of concentrating devices; and 2) the existence of solar radiation intermittent, periodic and unstable characteristics, vulnerability to the season, day and night. It is generally challenging to solve these core problems to significantly increase its competitiveness [27]. This is contrary to the steady energy demand for industrial heat throughout the year, which requires heat storage or auxiliary heat source to improve solar energy guarantee rate and the system's adjustable flexibility. It is especially important for trough solar thermal power generation systems [30]. Therefore, in order to obtain a wider development of solar industry thermal utilization, it is necessary to tackle the problem of lowconcentration concentrating technology and energy storage technology. 
Table 1 Application of solar heat for industrial processes [23]

\begin{tabular}{|c|c|c|c|c|c|}
\hline Sector & Process & $\begin{array}{r}\text { Temperature } \\
\text { Range }\left({ }^{\circ} \mathrm{C}\right) \\
\end{array}$ & Sector & Process & $\begin{array}{r}\text { Temperature } \\
\text { Range }\left({ }^{\circ} \mathrm{C}\right) \\
\end{array}$ \\
\hline \multirow[t]{4}{*}{ Chemicals } & Distillation & $100-200$ & Dairy & Sterilization & $100-120$ \\
\hline & Compression & $105-165$ & & Drying & $120-180$ \\
\hline & Cooking & $80-100$ & & $\begin{array}{l}\text { Boiler feed } \\
\text { water }\end{array}$ & $60-90$ \\
\hline & Thickening & $110-130$ & Tinned & Sterilization & $110-120$ \\
\hline Foods & Blanching & $60-100$ & food & Cooking & $60-90$ \\
\hline \multirow[t]{9}{*}{$\&$ beverages } & Scalding & $45-90$ & & Bleaching & $60-90$ \\
\hline & Evaporating & $40-130$ & $\begin{array}{l}\text { Timber By- } \\
\text { products }\end{array}$ & $\begin{array}{l}\text { Thermo } \\
\text { diffusion beams }\end{array}$ & $80-100$ \\
\hline & Cooking & $70-120$ & & Drying & $60-100$ \\
\hline & Pasteurization & $60-145$ & & $\begin{array}{l}\text { Pre-heating } \\
\text { water }\end{array}$ & $60-90$ \\
\hline & Smoking & $20-85$ & & $\begin{array}{l}\text { Preparation } \\
\text { pulp }\end{array}$ & $120-170$ \\
\hline & Cleaning & $60-90$ & & Fixing & $160-180$ \\
\hline & Sterilization & $100-140$ & & Pressing & $80-100$ \\
\hline & Tempering & $40-80$ & Wood & Steaming & $70-90$ \\
\hline & Drying & $40-200$ & & Compression & $120-170$ \\
\hline \multirow[t]{3}{*}{ Paper } & Bleaching & $40-150$ & & Cooking & $80-90$ \\
\hline & Cooking & $110-180$ & & Drying & $40-150$ \\
\hline & Drying & 95-200 & Bricks & Curing & $60-140$ \\
\hline Fabricated & Pickling & $40-150$ & \& Blocks & $\begin{array}{l}\text { Plastics } \\
\text { Preparation }\end{array}$ & $120-140$ \\
\hline \multirow[t]{4}{*}{ Metal } & Degreasing & $20-100$ & & Distillation & $140-150$ \\
\hline & Electroplating & $30-95$ & & Separation & $200-220$ \\
\hline & Phosphating & $35-95$ & & Extension & $140-160$ \\
\hline & Drying & $60-200$ & & Drying & $180-200$ \\
\hline Rubber\& & Drying & $50-150$ & & Blending & $120-140$ \\
\hline Plastic & Surface treatment & $20-120$ & Automobile & Water heating & -90 \\
\hline \multicolumn{6}{|l|}{ Machinery } \\
\hline$\&$ & Cleaning & $40-90$ & Leather & Cleaning & -120 \\
\hline \multicolumn{6}{|l|}{ Equipment } \\
\hline \multirow[t]{4}{*}{ Textiles } & Bleaching & $40-100$ & & Other processes & -90 \\
\hline & Coloring & $40-130$ & Metal & Heating & -180 \\
\hline & Drying & $60-90$ & & Washing & -160 \\
\hline & Washing & $50-100$ & Pharmacy & $\begin{array}{l}\text { Different } \\
\text { processes }\end{array}$ & $70-180$ \\
\hline
\end{tabular}

The paper is organized as follows. Section 1 introduces the background of solar thermal

140 utilization. In Section 2, the development of application and performance research of heat collection 141 systems are summarized. Section 3 presents a review on the development of heat storage systems 
including selection of phase change materials, structural design and performance research. In Section 4, the performance and capacity matching of the heat collection-storage coupling and heatcollection-storage-utilization systems are summarized. Section 5 aims at providing a case study of the application of a heat-collection and heat-storage coupling system. This section will also explore the impact of the thermal boundary conditions under the actual weather conditions on the thermal performance of the system. The main findings are summarized in Section 6.

\section{Development of heat collection system}

\subsection{Development of solar collectors}

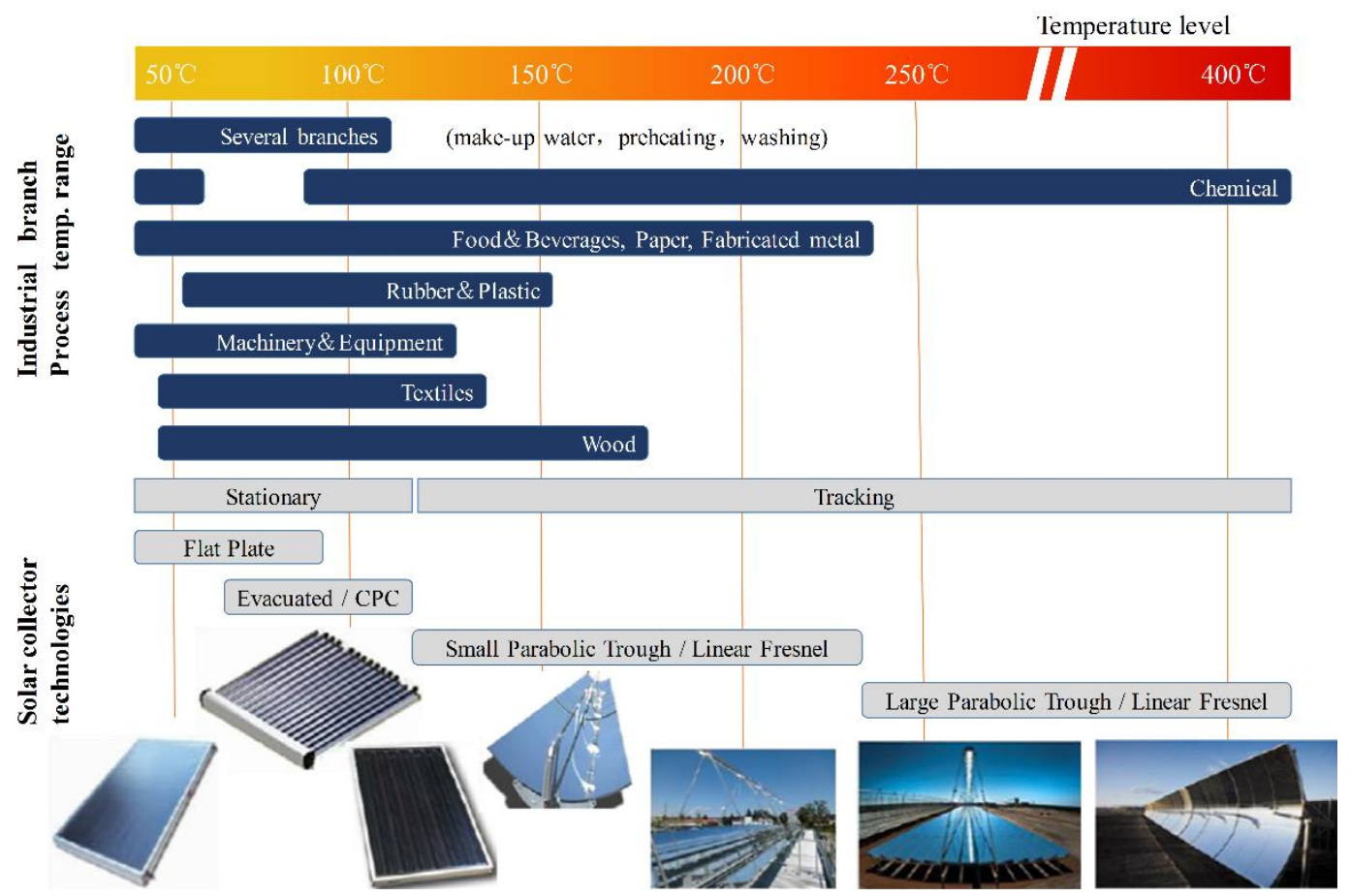

Fig. 4. Operation temperature of different types of solar collector for SHIP [13].

The core component of a solar thermal utilization system is the solar collector, which converts the solar radiation into the heat of the heat transfer medium. In the field of low-temperature heat utilization, flat plate collectors (FPC) and vacuum tube collectors (ETC) are mainly used [31]. Pandey et al. [32] found that solar FPCs can be used to trap solar thermal energy and use it for heating applications like water heating, room heating and other industrial applications. Some optical and heat transfer enhancement techniques can extend the temperature to a higher level, such as use nanofluid[33], transparent insulation material for FPCs (up to $150{ }^{\circ} \mathrm{C}$ ) [34], and the use of inert gas or an ultra-high vacuum (up to $150^{\circ} \mathrm{C}$ ) [35]. ETC combined with Compound parabolic collectors (CPC) can achieve 3-10 times of concentrated light, and can provide temperatures up to150 ${ }^{\circ} \mathrm{C}$ [36]. The concentrating collectors are used for medium and high temperature heat utilization, while parabolic trough concentrating (PTC), linear Fresnel concentrating (LFC), non-imaging concentrating (CPC) are commonly used for medium and low concentrating in industrial applications [24], as well as some novel types such as semi-passive tracking collector [13]. Different collectors can provide different heat transfer working temperature zones, as shown in Figure 4 [37]. Kalogirou [38] reviewed and compared FPC, CPC, ETC, PTC, LFC, parabolic dish collector (PDC) and heliostat field collectors (HFC), and simulated the output of SHIP systems for different temperatures. PDC and HFC are two-axis tracking concentrating, which is mainly used for solar 
thermal power generation [20]. It was found that in the SHIP field, considering the maturity and economy of technology, PTC is most suitable for heating in the required temperature zone [39].

\subsection{Selection of solar collectors}

Since concentrated collectors have a great potential in various fields of industrial applications such as mining, food process, chemical synthesis, textiles, machinery and equipment manufacturing, pulp and paper. the collectors used in each case should be selected carefully. Several aspects such as suitable operation temperature, higher efficiency, integration pattern with the industrial process, cost and space availability should be considered.

For industrial processes that highly depend on the temperature range, the solar collector should provide a specific thermal demand with a certain energy grade. According to different temperature ranges, there are mainly several types of collectors used in the SHIP fields, including FPC, ETC, PTC, CPC and LFC. Mahesh et al. [40] presented that the traditional flat plate, evacuated tube and high efficient parabolic trough collector can provide temperature ranges of $60-80^{\circ} \mathrm{C}, 80-150^{\circ} \mathrm{C}$ and $150-400^{\circ} \mathrm{C}$, respectively. For the specific thermal demand, it is necessary to select the collector that can provide a narrow temperature range.

The heat transfer fluid could be water, air or oil. Air is commonly utilized in the food process and drying for agricultural and forestry products [41]. Water is used for heating applications or preheating of boiler feed water, while oil often used for an indirect heat exchange system with a thermal energy storage unit [42]. The integration patterns mainly include: (a) Pre-heating of water where heat energy is required for evaporation. However, the condensate can return a high temperature so the efficiency of the non-concentrating collector is reduced [3]. (b) Integration on the distribution level where high temperatures (mostly steam) are required so only concentrating solar collectors can be used. This provides the greatest flexibility as it is not linked to a specific process [43]. (c) Another important way to integrate solar thermal energy is direct coupling with a specific process. However, when the process is changed or stopped, it can be challenging to use the energy which is rather inflexible [44]. Benoit et al. [45] presented the variations of the convective heat transfer coefficients in the stable operation temperature ranges of the HTFs and discussed recent developments on new HTFs working at least $700{ }^{\circ} \mathrm{C}$.

The design of innovative structures or the selection of more suitable optical materials can ensure a solar collector to operate in a higher efficiency [46], and this will be discussed in Section 3.3. In addition, the economic efficiency was considered. For example, Mohan et al. [47] analyzed three different solar collectors such as FPC, ETC and CPC. It can be concluded that a lowest payback period of 6.75 years was achieved by solar thermal power with evacuated tube collector with a gross area of $216 \mathrm{~m}^{2}$.

\subsection{Performance of solar collectors}

From the theory of photo-thermal conversion, it can be seen that the thermal performance of solar energy is related to the type, structure, optical efficiency, working temperature, solar radiation and ambient temperature. The main indicator is the instantaneous collector efficiency [8]. Various types of experimental set-up [48] and mathematical models [49] of the Parabolic Trough Solar Collectors have been reviewed, and the modelling methods were compared [50]. Zou et al. [51] 
proposed a special small-sized parabolic trough solar collector, and extensive experiments were conducted to evaluate the characteristics of the proposed PTC. The results showed that the PTC could collect solar radiation efficiently. Kumaresan et al. [52] carried out experimental and numerical studies of thermal performance enhancement in the receiver part of solar parabolic trough collectors. Conrado et al. [48] presented various types of mathematical models, simulation and numerical methods, and experimental set-up of the PTCs. Based on the performance studies of various types of specific collectors, some empirical formulas were obtained, as shown in Table 2 [53], where $\eta_{\mathrm{i}}$ is the instant efficiency of solar collector system, $T_{\mathrm{m}}$ is the average temperature of collector, $T_{\mathrm{i}}$ is the inlet temperature of heat transfer fluid, $T_{\mathrm{a}}$ is the temperature of environmental air, and $I$ is the instant solar irradiance. It can be seen that, except for the coefficients, the form of the formula and the parameters involved are almost identical. Therefore, in most cases, it does not require customized design and manufacturing once the performance curve is determined.

To enhance the thermal performance and expand the temperature range, appropriate optimization of structure or materials has been conducted. For the new collectors with a special structure, the main focus is on the optimization of its structure, optics and heat transfer to improve the efficiency [54], and obtain the heat collecting performance through experiments, simulation or advanced prediction methods [55]. Yang et al. [56] present a dynamic 3D volume element model of PTC considering the semi-finite optical model, and analyzed the influence factors on the performance described by the first and second laws in order to optimize the structure and operating parameters. Gong et al. [57] explored the enhanced heat transfer performance of a PTC with pin fin arrays inserting into the absorber tube, by using Monte Carlo ray tracing method. Bellos et al. [58] analyzed the performance of PTC with internally finned absorbers for various operation conditions by using SolidWorks Flow Simulation. For high-temperature collectors, multi-objective performance optimization with non-dominated sorting genetic algorithm has been used [59]. A new design of a collector with a spherical shaped reflector and the tracking components was also reported, and its overall efficiency can reach to $50 \%$ and the temperature can go up to $200{ }^{\circ} \mathrm{C}$ [60]. A LFC with two-axes tracking and cavity receiver was developed and its temperature can reach $250^{\circ} \mathrm{C}$ [53].

Table 2 Efficiency equation of different types of collectors [53]

\begin{tabular}{|c|c|c|c|}
\hline Solar collector & Tracking & $\begin{array}{c}\text { Operating } \\
\text { temperature }\left({ }^{\circ} \mathrm{C}\right)\end{array}$ & Efficiency equation \\
\hline Flat plate & $\begin{array}{l}\text { Non- } \\
\text { tracking }\end{array}$ & $30-100$ & $\begin{array}{c}\eta_{i}=0.732-3.411^{*}(T m-T a) / I-0.294^{*}(T i \\
-T a)^{2} / I\end{array}$ \\
\hline Evacuated tube & $\begin{array}{l}\text { Non- } \\
\text { tracking }\end{array}$ & $50-100$ & $\begin{array}{c}\eta_{i}=0.62-3.395^{*}(T m-T a) / I-0.002^{*}(T i \\
-T a)^{2} / I\end{array}$ \\
\hline $\begin{array}{l}\text { Compound parabolic } \\
\text { concentrator }\end{array}$ & $\begin{array}{l}\text { Non- } \\
\text { tracking }\end{array}$ & $60-240$ & $\begin{array}{c}\eta_{i}=0.644-0.749^{*}(T m-T a) / I^{*} 0.005^{*}(T m \\
-T a)^{2} / I\end{array}$ \\
\hline Parabolic trough & Single axis & $60-300$ & $\begin{array}{c}\eta_{i}=0.71-0.3581^{*}(T m-T a) / I-0.0019^{*}(T m \\
-T a)^{2} / I\end{array}$ \\
\hline Arun 160 (Dish) & Double axis & up to 250 & $\eta_{i}=0.65-0.40^{*}(T m-T a) / I$ \\
\hline $\begin{array}{l}\text { Linear Fresnel } \\
\text { reflector }\end{array}$ & Single axis & up to 300 & $\begin{aligned} \eta_{i}=0.635-0.0265^{*}(T m-T a) / I \\
-0.00043^{*}(T m-T a)^{2} / I\end{aligned}$ \\
\hline
\end{tabular}


Solar heating shows a huge potential for industrial processes, while it has not been applied much in the engineering practice. Even if there are commercially customized solar collectors, the coupling characteristics of the heat collecting unit and other units in the system is still an unsolved problem. Much progress has been made on single heat collecting unit, but limited research has been carried out to match heat storage, heat mode and their coupling characteristics. It is necessary to analyze the coupling relationship between each subsystem and exploit the heat transfer and flow laws in line with the actual situation.

\section{Development of heat storage system}

\subsection{Development of heat storage devices}

Thermal storage technology (TES) can alleviate the conflict between thermal energy supply and the demand in terms of time, intensity and space. Common short-term heat storage includes sensible heat storage, phase change heat storage, and chemical reaction heat storage (reversible endothermic/exothermic reaction) [61]. Among them, sensible heat storage is the most mature and commercially viable heat storage method at present. Phase change heat storage is a hot topic in the recent decades, such as the PCMs and applications [62], the heat transfer problems [63] and some researches concerning the PCMs special for solar heating system [64]. Liu et al. [65] reviewed the development in high temperature TES over the past decade with a focus on sensible and latent heat storage and discussed high temperature corrosion and economic aspects of these systems. Miró et al. [66] found that the on-site TES systems have received the most attention in the manufacturing industry.

The sensible heat storage is divided into three types: liquid sensible heat storage, solid sensible heat storage, and liquid-solid combined sensible heat storage [67]. HTF is the same as heat storage material called direct heat storage. It is simpler and more efficient because it reduces one heat exchange step and avoids poor heat exchange between HTF and heat storage material. Molten salt, mineral oil and synthetic oil can be used as the working fluid. In addition, indirect heat storage needs to comprehensively consider the cost of antifreeze and heat storage materials. These two schemes were applied to the Solar Energy Generating Systems (SEGS) trough system in the United States for on-site experiments. The indirect heat storage showed the potential for later development [68]. The application of high temperature conditions created conditions for the Rankine cycle efficiency to increase to $40 \%$ [69]. Considering the structure, function, cost and technical maturity of the system, direct heat storage has a great potential in the field of SHIP applications, and heat transfer/heat storage materials such as mineral oil is very suitable for temperature below $300{ }^{\circ} \mathrm{C}$. The direct heat storage usually takes a double tank system; one hot tank is used for melting while one cold tank is used for solidification [70]. However, sometimes the heat storage takes a single tank system, where the middle oblique temperature layer separates the hot and cold working medium into upper and lower parts [71]. The single tank system saves initial investment and is designed to replace the two tank system. Kim et al. [72] presented single tank-based thermal energy storage to reduce costs and installation space. The single tank used a porous block to make easy passage of the molten salt and reduce the flow pressure drop. Zhang et al. [73] explored the performance of a solar and coal dual-source boiler with a thermocline energy storage, and found that the energy storage efficiency improved by $0.5-0.8 \%$ per hour.

Phase change heat storage has the advantages of large heat storage density, easy process control, 
stable temperature during heat storage/heat release process, etc. Extensive research has been performed, especially for applications where heat supply is discontinuous or supply and demand are not coordinated. It also has advantages in concentrating solar thermal power generation systems. The current research focuses on the development of new phase change materials (PCMs) and characterization of their physical parameters, thermal stability, and thermal conductivity enhancement, the structure of thermal storage equipment, and PCMs and equipment materials compatibility.

Some investigations are related to the latent heat storage (LHS) and sensible heat storage (SHS).The low-temperature solar utilization of a heating water system for daily applications was explored [74]. It is found that the latent heat storage with paraffin wax as PCM can store $40 \%$ more heat energy than the sensible heat storage. Fan et al. [75] conducted a review covered a variety of PCMs, operating conditions, heat exchange and thermal energy storage arrangements. Alva et al. [76] found that the thermal conductivity of the PCM can be improved by dispersing high thermal conductive particles like carbon, graphite or metals into the PCM. Tay et al. [77] conducted that the use of additional metallic material and increasing heat transfer surface area such as fins can improve the heat transfer rate of the PCM. Vasu et al. [78] summarized that the compatibility of the container materials with PCM plays an important role because PCMs are normally encapsulated in containers.

\subsection{Selection and thermal properties of PCMs}

In the design process of a phase change heat storage system, it is first necessary to select or prepare a suitable phase change material. In addition to considering the thermal conductivity of its key physical parameters, the selection and preparation of phase change energy storage materials in combination with a medium temperature collector system must meet several physical and chemical properties [63]. Wei et al. [79] found that the selection of phase change materials for TES systems should meet thermal performance, physical performance, dynamic performance, chemical performance, economic performance, and technical performance requirements. Molten salt is the first choice for the field of high-temperature heat utilization in solar energy. It is usually composed of alkali metal or alkaline earth metal and halide, $\mathrm{SO}_{4}{ }^{2-}, \mathrm{CO}_{3}{ }^{2-}, \mathrm{NO}_{3}{ }^{-}$and $\mathrm{PO}_{4}{ }^{3-}$. In contrast, the alkali metal nitrate system can better meet the above requirements, and be particularly suitable for medium and high temperature heat storage media [80]. Zhang et al. [81] adopted the eutectic molten salt as the PCM to make the utilization of solar energy at medium temperature of around $200{ }^{\circ} \mathrm{C}$ more efficiently, and it will be helpful for the application using molten salt for solar energy storage. Pfleger et al. [82] and Jin et al. [83] revealed that Hitec $\left(\mathrm{NaNO}_{3}-\mathrm{NaNO}_{2}-\mathrm{KNO}_{3}\right)$ and Solar salt $\left(\mathrm{NaNO}_{3}-\mathrm{KNO}_{3}\right)$ are the two molten salts that have been extensively used in Concentrated Solar Power (CSP). At the same time, the viscosity of the specific components of emerging ternary nitrates $\left(\mathrm{Ca}\left(\mathrm{NO}_{3}\right)_{2}-\mathrm{NaNO}_{3}-\mathrm{KNO}_{3}, \mathrm{LiNO}_{3}-\mathrm{NaNO}_{3}-\mathrm{KNO}_{3}\right.$ and $\mathrm{Ca}\left(\mathrm{NO}_{3}\right)_{2}-\mathrm{LiNO}_{3}-\mathrm{KNO}_{3}$ mixtures) were measured in the high temperature areas, which have shown their potential applications in CSP systems.

In addition, in order to make molten salt act as a flow heat transfer medium, new formulations or additives that have lower melting points and a wider temperature range of use have been developed. Raade [84], for instance, developed a eutectic mixed nitrate of five components with a melting point reduced to $65^{\circ} \mathrm{C}$. Tian et al. [85] prepared the physical performance enhanced molten salt by adding $\mathrm{Mg}$ particles. Zhou $[86,87]$ carried out a study of a eutectic salt of $\mathrm{LiNO}_{3}-\mathrm{NaCl}$, and 
found that it was very suitable for the medium temperature range because the chemical stability was below $400{ }^{\circ} \mathrm{C}$. Cunha et al. [88] presented a comprehensive review of PCMs with phase transition temperatures between 0 and $250{ }^{\circ} \mathrm{C}$. Organic compounds and salt hydrates seem to be more promising below $100^{\circ} \mathrm{C}$ and eutectic mixtures are more suitable for applications where temperature varied from 100 to $250^{\circ} \mathrm{C}$. Bradshaw et al. [89] disclosed a series of patents for low-melting mixed molten salt heat transfer and heat storage media. For industrial thermal loads at temperatures below $250{ }^{\circ} \mathrm{C}$, the phase transition temperatures of these molten nitrates are suitable.

Faced by a wide variety of phase change heat storage materials (at least 160,000), it is a very complicated task to identify the most suitable heat storage material for a particular application. It is also a key issue to promote the high-temperature heat utilization of solar energy. In the field of solar thermal power generation, due to the production needs, the impact of the selection of heat storage materials on system performance and cost have been analyzed from an operational perspective. Ren [90] prepared 36 kinds of mixed carbonate molten salts, and analyzed their thermal physical properties, as well as the cost. Thirteen types of ternary carbonate salts were recommended for latent heat storage. Bradshaw et al. [91] evaluated the use of various binary nitrates as single phase heat transfer fluids for solar tower absorbers and analyzed the effects of the chemical and physical properties of molten salts on thermoelectric systems. However, this experimental study was directed to the case where a liquid molten salt was used as a heat transfer heat storage medium, and did not include the physical properties in the solid state. Ruegamer et al. [92] compared the investment cost and the levelized cost of energy of different heat storage materials and heat storage systems with different heat storage scales in the trough concentrating power generation system. Jacob et al. [93] investigated the capital cost (CAPEX) of each system including the tank, storage material, encapsulation cost (if applicable) and allowances for construction and engineering. The liquid sodium system was found to result in a higher embodied energy and CAPEX than other previously studied TES systems.

When a material is actually selected, it is difficult to ensure that the parameters of the thermal performance are dominant. For example, a material with a large thermal conductivity may have a small specific heat capacity. Fernandez et al. [94] used the CES database to evaluate and optimize materials for the $150-200{ }^{\circ} \mathrm{C}$ sensible heat storage based on the minimum cost principle. However, this method is only suitable for the material selection with well-defined analytical solutions. However, for the latent heat storage process including phase transition and phase interface migration, the applicability of this method is poor, and the numerical model is usually used to simulate the heat transfer process. Pointner et al. [95] discussed four different numerical models that can be used to investigate phase change processes within latent heat storage and compared their performance in terms of accuracy, convergence behavior and computational efficiency.

\subsection{PCM thermal conductivity enhancement and structure optimization of LHS system}

Most of the available PCMs have relatively low thermal conductivity. The thermal conductivity of inorganic PCMs such as hydrated salts and molten salts is only about $0.5 \mathrm{~W} / \mathrm{m} \cdot \mathrm{K}$, which directly affects the heat storage and heat release rates of the PCMs [96]. Low thermal conductivity is one of the most important factors restricting the large-scale application of phase change heat storage. Therefore, strengthening the physical parameters such as PCM thermal conductivity and enhancing the heat transfer of the heat storage devices have always been the focus of research in the field of 
phase change heat storage. At present, there are several ways to enhance phase change heat transfer, such as improving the aspect ratio of heat storage materials, filling materials with high thermal conductivity, microencapsulation packaging technology, and combining with heat pipe heat pumps.

Al-Maghalseh et al. [97] discussed the heat transfer intensification methods including application of fins, filling materials, nano-fluids, nano-particles, microencapsulation and the thermal conductivity enhancement method. Nomura et al. [98] reported the synthesis of a core-shell type microencapsulated PCM (MEPCM) consisting of Al-25 wt\% Si microspheres (mean diameter of $36.3 \mathrm{~lm}$ and melting temperature of $\left.577^{\circ} \mathrm{C}\right)$ as the core $(\mathrm{PCM})$ and $\mathrm{Al}_{2} \mathrm{O}_{3}$ as the shell. The results showed that the heat capacity measured for this material was five times higher than that of conventional solid SHS materials. Zhang et al. [99] developed a novel microencapsulated PCM by in situ polymerization to produce high encapsulation capacity and leakage-prevention performance. Li et al. [100] established a new high-temperature packed-bed thermal energy storage system (PBTES) with macro-encapsulation of molten salt PCM.

Increasing the aspect ratio of the heat storage material and filling the material with high thermal conductivity are common strengthening methods. Fixed high thermal conductivity inserts, adding additives, introducing metal skeletons or adding honeycombs, fins, brushes are among the main methods used to enhance the thermal conductivity of PCMs [75, 101], especially the addition of carbon fiber [102-104], metal foam or powder [105-106], preparation of micro-nano composite [107-110] or EG [111-113]. For example, Fukai et al. [103] studied the effect of random carbon fiber and carbon fiber brush on the thermal conductivity of paraffin, and the results showed the thermal conductivity of the mixture can be improved significantly. Wang et al. [112] proposed a phasechange composite of double-layer carbon grid structure. The thermal conductivity of the original paraffin wax increased to 7.5 times when the EG content of expanded graphite reached $20 \%$. Xiao et al. [111] analyzed the melting and solidification processes before and after the addition of metal foam in molten salt, and found that increasing foamed copper and foamed nickel reduced the solidification time by $28.8 \%$ and $19.3 \%$, respectively. Das et al. carried out a numerical simulation and investigated the melting process of organosilane PCMs both in horizontal [109] and vertical [110] shell-and-tube LHS devices. The results showed that the addition of nanocomposites increased the thermal conductivity of the PCM to a certain extent. Mixing $1 \%$ by volume (vol\%) of different morphological nanomaterials can increase the melting rate by $2 \%$ with spherical nanoparticles, increase the melting rate by $27 \%$ and $40 \%$ with single-walled carbon nanotubes and graphite nanosheets respectively, and the corresponding melting time reduced by approximately $15 \%$ and $25 \%$. Ibrahim et al. [114] revealed that heat transfer enhancement in latent heat thermal energy storage (LHTES) systems can be achieved through either geometric configuration and/or thermal conductivity enhancement. The use of extended surfaces such as fins or heat pipes is a common technique for heat transfer enhancement. Cunha et al. [88] explored the heat enhancement methods including extended metal surfaces, using carbon, metal matrices and conductive powders, and direct heat transfer techniques. Merlin et al. [115] presented an experimental thermal energy storage using a phase change material associated with various configurations of conductive structures such as finned exchangers, graphite powder and Expanded Natural Graphite (ENG) matrix. The results showed that the thermal conductivity of the ENG/PCM composite was about 100 times greater than the conductivity of the PCM alone. Chang et al. [116] introduced concentric rod and eccentric rod as turbulators, and analyzed the flow and convective heat transfer characteristics of molten salt in a 
parabolic trough receiver. The result showed that both concentric rod insert and eccentric rod insert can enhance the heat transfer performance effectively. Sandeep et al. [117] examined the feasibility of various heat transfer augmentation techniques for a PTC receiver. It was concluded that for PTC application, using insert with base fluid was beneficial in the laminar region and nanofluid with insert was justified for the turbulent regime. Tao et al. [96] introduced that the available enhancement methods can be classified into three categories, including using high thermal conductivity additives and porous media to enhance PCM thermal conductivity; using finned tubes and encapsulated PCMs to extend heat transfer surface; and using multistage or cascaded LHS technique and thermodynamic optimization to improve the heat transfer uniformity.

Except for improving the PCM itself, structure optimization of the latent heat storage device is also important to improve heat transfer performance. Ogoh et al. [118] explored the influence of the number and distribution of fins in cylindrical phase change storage tanks on heat storage characteristics. Liu et al [119] optimized the structure of a shell-and-tube heat exchanger with a metal foam and analyzed the structural parameters of the metal foam and the influence of the heat transfer medium inlet temperature on the heat storage characteristics. Al-Abidi et al. [120] conducted a structural reinforcement analysis of the internal fins and outer fins of a three-tube heat storage heat exchanger by using two-dimensional numerical modeling and explored the effect of the heat exchanger material on the heat storage rate for the number, length, thickness, and number of fins. Mat et al. [121] carried out simulation and experimental investigation on a three-tube phase change heat exchanger, and studied the influence of different heating forms and fin arrangement inside and outside. The results showed that the inner and outer fins can greatly reduce the melting time. Pizzolato et al. [122] proposed an optimization method based on topology and CFD to simulate the important role of natural convection in heat transfer enhancement in phase change storage tanks. Yang et al. [123] used simulation to study the role of inner ring fins in shell-and-tube heat storage tanks and optimized the structure and size. Shinde et al [124] conducted an enhanced heat transfer analysis on the phase change heat storage device of the organic Rankine cycle solar thermal power plant and established a three-dimensional simulation model to obtain the optimal number, thickness, and height of the fins. Veeraragavan et al. [125] explored the influence of lateral heat losses from a PCM storage tank on the performance of a storage integrated concentrating solar power system by means of an analytical model. It revealed that a high absorber area enabled the system with a high thermal efficiency.

For the performance of the heat storage device, the heat storage of the direct heat storage is relatively simple to calculate. The theoretical and experimental challenges related to the thermal performance of the double tank and the single tank systems are mainly temperature stratification. Senthil Kumar [126] analyzed the effect of the addition of PCM encapsulated in spherical capsules at the top of a hot water storage tank for stratification enhancements during the charging process. The results showed that PCM capsules increased the stratification capability as the temperature difference between the inlet HTF and PCM melting temperature was increased. Bouhal et al. [127] carried out the thermal stratification inside a standard hot water storage tank. It was shown that thermal stratification inside the storage tank is dependent on the positions of the flat plate. Wang et al. [128] designed a novel equalizer in order to improve the thermal stratification of a heat storage tank. It was shown that the equalizer performed best, and the storage tank had a better thermal stratification when the flow rate was $3 \mathrm{~L} / \mathrm{min}$. Moncho-Esteve et al. [129] used Computational Fluid 
Dynamics (CFD) to study thermal stratification during the charge process in a cylindrical water tank.

Different phase change heat storage devices and different PCMs have distinct thermal properties. Therefore, the heat transfer performance of the phase change heat storage unit is characterized by the heat storage efficiency and includes the heat storage/release rate index and the exergy efficiency based on the second law of thermodynamics.

\subsection{Research gaps}

As an obstacle for PCM in SHIP application, its low conductivity is always considered as a foremost factor. Very limited investigations have been performed to address the PCM based heat performance enhancement. While the effects of thermal conductivity and phase-change temperature on storage system performance are generally separately studied, it is worth combining these two factors in future investigations.

\section{Matching and performance of heat collecting/storage/utilization coupling systems}

\subsection{System matching relationship and performance}

The static matching of the heat collection-storage-utilization units and the dynamic matching relationship on the heat transfer rate determine the operating performance of the SHIP system. Due to the slow development of the SHIP system, the field of solar thermal power generation has attracted more attention. Therefore, the current research status is mostly in the field of power generation.

In terms of static matching of sub-unit size, Powell et al. [28] established a heat transfer model of a trough solar thermal power generation system from the heat collection, heat storage to the boiler heat transfer. The operation dynamics of the system were respectively analyzed using a simple control strategy and an optimal control strategy. It was found that the solar energy guarantee rate of the system increased from $47 \%$ to $70 \%$ on sunny days after the increase of $8 \mathrm{~h}$ heat storage capacity of a TES. Baghernejad et al. [130] optimized the operation of a hybrid thermal power plant with conventional energy and solar energy, and combined the energy balance and analysis method to optimize the important parameters such as the scale of solar energy field, the rate of return, the consumption of conventional energy, and the length of solar energy operating time. Mohamadi et al. [131] carried out a theoretical modeling and experimental study on a combined solar thermal storage device. The optimized results showed that different heat storage media should be selected with different time period in order to increase heat storage without increasing the heat collection area. Heller et al. [132] established a heat transfer model for a solar thermal power generation system with a thermal storage device in a rock bed with an inclined temperature layer, and simulated the performance of the whole generation and heat storage system. Behar et al. [20] carried out a detailed modeling that comprised the heat transfer in the receiver tube, optics of the collector and the heat losses from the piping for the solar field. Zhao et al. [133] carried out a survey on achieving a higher solar-to-electricity conversion efficiency through solar-fossil hybrid thermal power systems as compared to a solar-only power plant. The results indicate that the moderate-temperature solar and fossil hybridization technology can provide a promising direction for efficient utilization of lowgrade solar heat. 
In terms of dynamic matching such as operating parameters, Menéndez et al. [134] conducted a mathematical modeling and control study fora trough-type concentrating solar thermal system with a molten salt heat storage device. Zhao et al. [135] established a physical model and a dynamic simulation model of a heating system composed of a plate collector, a phase change heat storage, an auxiliary heat source and a plate heat exchanger. The real-time parameters in 7 operation modes were simulated, which provided a theoretical reference for design optimization. Li et al. [136] investigated the dynamic efficiencies of an open-loop air receiver and a thermal energy storage unit numerically. Meanwhile, an air receiver and thermal energy storage experimental platforms were built to validate the simulation models. Ni et al. [137] studied the influence of intensity of solar radiation on the daytime performance of a solar-ORC system.

For solar thermal systems with heat storage device, the degree of flexibility of the system is increased, the operation mode is more diverse, and the control strategy is more complex. Cole et al. [138] analyzed the thermal storage in the building heating, solar thermal power generation and even the chemical industry to increase the flexibility of the system. Multi-parameter constraint control is required to maximize the benefits of heat storage devices. Khalilzadeh et al. [139] optimized the daily operation of solar thermal power plants with heat storage devices, and established a series of models with nonlinear control equations and verified methods. Taking the maximum daily generation time and maximum benefit as the optimization objectives, the results of two single objectives and one multi-objective optimization were compared. The first single objective optimization showed that the heat storage unit increased the power generation time by 7 hours per day, and the second single objective optimization showed that the heat storage unit provided a $13.5 \%$ profit increase. The multi-objective compromise optimization showed that the heat storage unit can increase the power generation time by 5 hours and increase the profit by $8.1 \%$. Arkar et al. [140] presented the design and thermal response modeling of a solar air heating system, which consists of an air vacuum tube solar collector and latent heat storage. The analysis showed that a solar heating fraction of $63 \%$ can be achieved in an energy efficient, lightweight building.

\subsection{Dynamic simulation of system performance}

The establishment of dynamic heat transfer models of solar energy systems can reliably reflect the heat transfer behavior and performance of the system. It is also the basis of system matching and optimization. To obtain the real melting (heat storage) and solidification (heat release) behaviors, it is required to explore the influence of the solar energy collecting field on the heat storage and examine the influence of the terminal heat on the heat release. Theoretical modeling, numerical simulation and experimental investigation are often used to pursue this goal. Here the heat storage process is taken as an example to illustrate the current research progress. As the melting and solidification processes of PCMs is a complex heat transfer process involving two phases, there are generally three physical phenomena in the process of phase transition: phase transition, heat conduction and convection. Generally, the heat transfer in the liquid region is dominated by convection, and the solid area is dominated by heat conduction, making it more complex than a single conduction or convection process. Also, the solid-liquid phase interface is a nonlinear motion process, which is difficult to obtain precise analytical solutions. The exact solution can be obtained, such as the representative Neumann solution [141] if only considering the first type of thermal 
finite boundaries and multicomponent PCMs, considering the process of natural convection, or the second or third type of thermal boundary conditions, the approximate analytical solutions can only be obtained by means of isotherm transfer, heat balance integral and periodic solution. However, the approximate solution is too complex to be used conveniently in practical problems.

Since it is difficult to predict the mathematical analytic solution and the approximate analysis solution, in many cases, only numerical simulations were used. Many studies adopted numerical simulations to examine the heat transfer characteristics of phase change materials, which has gradually become an efficient and useful research method in the field of phase change energy storage. Numerical simulation methods such as finite difference method and finite element method are more convenient and effective in solving moving boundary problems. Software simulation has become a conventional method for optimizing heat storage device. For example, Yang et al. [123] used software simulation to study the effect of annular fins in a tubular heat storage tank, and optimized its structure and size. Pizzolato et al. [122] proposed an optimization method based on topology and CFD to analyze the important role of natural convection in heat transfer enhancement in a phase-change heat storage tank. Hachicha et al. [142] used a numerical-geometrical method based on the ray trace and finite volume method to determine the solar flux distribution around the absorber tube with a high accuracy. Calise et al. [143] investigated an innovative solar-geothermal polygeneration system and developed a dynamic simulation model in TRNSYS. Allouche et al. [144] carried out a simulation study using TRNSYS to meet the cooling needs of a $140 \mathrm{~m}^{3}$ space during the summer season in Tunis, Tunisia. It was found that the application of a relatively small hot storage tank led to the highest solar fraction (92\%). Fornarelli et al. [145] examined a latent heat storage system for concentrated solar plants (CSP) by means of CFD simulations. The results revealed that the enhanced heat flux, due to natural convective flow, reduced about $30 \%$ the time needed to charge the heat storage.

Numerical simulations and corresponding verification tests are usually performed under the first type of thermal boundary conditions at constant wall temperature. However, there are only a few studies that combined solar energy collection unit with phase change heat storage unit and these studies mainly focused on the low temperature heat utilization of solar energy, especially the household solar water heating systems. A number of studies also focused on the solar thermal power systems in the field of high temperature utilization of solar energy. Due to the slow process of medium-high temperature heating and cooling, the cost of one-time investment for the experiment platform is also high. In order to save the cost of experiments and shorten the research period, numerical analysis methods are usually adopted. Shinde et al. [124] analyzed the enhanced heat transfer of the phase change heat storage device of an organic Rankine cycle solar thermal power plant, and established a 3D simulation model in order to obtain the optimal number, thickness and height of fins. Nithyanandam et al. [146] proposed a rigorous calculation model for a phase-change heat storage device for solar concentrated power generation. The dynamic heat storage reaction under the thermal boundary condition of variable inlet temperatures was then simulated. Although this paper mainly focuses on the matching relation between the heat collection and heat storage units and the dynamic characteristics of the whole system, it also provided a theoretical reference for numerical modeling under variable temperatures and thermal boundary conditions. 
To analyze the matching relationship and dynamic characteristics of the heat transfer in the PCM-based storage system, it is inevitable to deal with the motional solid-liquid boundary problem even though difficult to solve. Because the state parameters such as liquid fraction are time-varying and can be obtained via simulation, it is possible to solve the motional solid-liquid boundary by combining experiment evaluation with numerical simulation. The key issue to build a such a hybrid model is to establish the mapping relationship between the phase change process, boundary condition and operation time. It is also necessary to establish a dynamic model to study the heat transfer characteristics of the heat-collecting and heat-storing coupled system, as well as the heatreleasing and heat -utilization coupled system.

\section{A case study: performance of a system coupled heat collecting with heat storage}

\subsection{Boundary condition of heat transfer}

According to the basic theory of heat transfer, there are three thermal boundary conditions, among which the first thermal boundary condition is the temperature boundary, in which the heat temperature of the heat material is constant. The second boundary condition is the boundary of heat flux, in which the heat flux is constant. The two boundary conditions are described in Eqs. (1-2).

$$
\begin{gathered}
t_{w}=C_{1} \\
q_{\mathrm{w}}=-\lambda\left(\frac{\partial T}{\partial n}\right)_{\mathrm{w}}=C_{2}
\end{gathered}
$$

Where $t_{w}$ is the wall temperature, $C_{1}$ and $C_{2}$ are the constants, $n$ is the normal of the area boundary, $q_{\mathrm{w}}$ is the heat flux density in the outer wall and $\lambda$ is the material thermal conductivity.

For the heat exchanger to storage heat, the latent heat and the sensible heat are combined and Eq.(3) is commonly used. $K$ is the total heat transfer coefficient, where the corresponding thermal resistance is combined as $R_{1}, R_{2}$ and $R_{3}$, as shown in Fig. (4). Because the thermal conductivity of the PCM is far lower than the metallic thermal conductivity, $R_{2}$ and $R_{3}$ are far lower than $R_{1}$ and can be ignored. $R_{1}$ is the combination of the heating area thermal conductivity and the phase boundary thermal conductivity.

$$
Q=K A \cdot \Delta t_{m}
$$

$$
K=1 /\left(R_{1}+R_{2}+R_{3}\right)
$$

where $\mathrm{Q}$ is the total heat transfer capacity, $A$ is the heat transfer area, $\Delta t_{\mathrm{m}}$ is the logarithmic mean temperature difference, $R_{1}$ is the heat resistance of solid-liquid PCM, $R_{2}$ is the heat resistance of the tube wall, and $R_{3}$ is the convection heat resistance between the HTF and the tubes.

\subsection{Effect of heat boundary conditions on heat transfer characteristic}

\subsubsection{The first boundary condition}

A numerical simulation study was carried out for a specific heat collecting-storage-utilization system, whose model establishment, setting and reliability verification were all reported in a previous study [147]. The boundary conditions of the latent heat thermal energy storage were respectively set as constant wall temperature $t_{\mathrm{w}}=270,260,250^{\circ} \mathrm{C}$, where the temperature range was 
matching with the constant temperature obtained from the actual solar heat collector. The initial temperature of the $\mathrm{PCM}$ was $25^{\circ} \mathrm{C}$, the melting and heat transfer processes of the $\mathrm{PCM}$ under three heat source temperatures were calculated. The temperature, mass fraction of the liquid phase, and heat transfer flux and other parameters variation during the 360 minutes were obtained and are shown in Figs. 5-7.

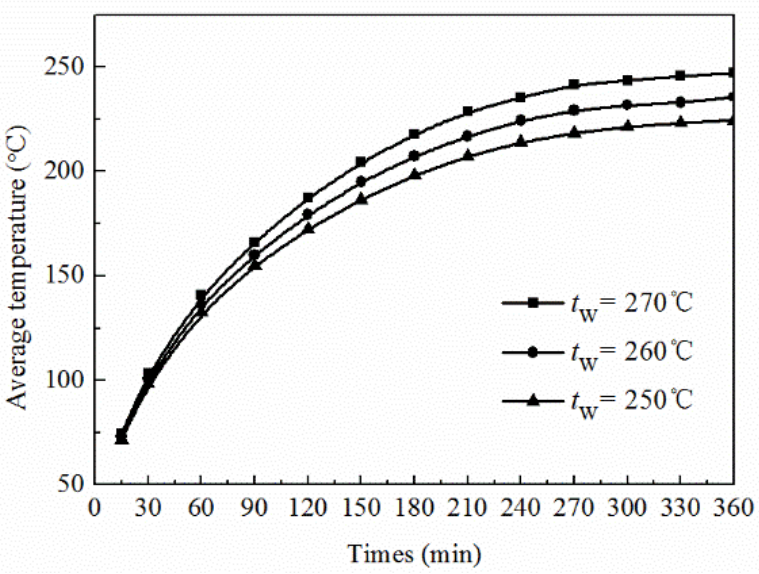

Fig. 5. PCM average temperature in the melting process.

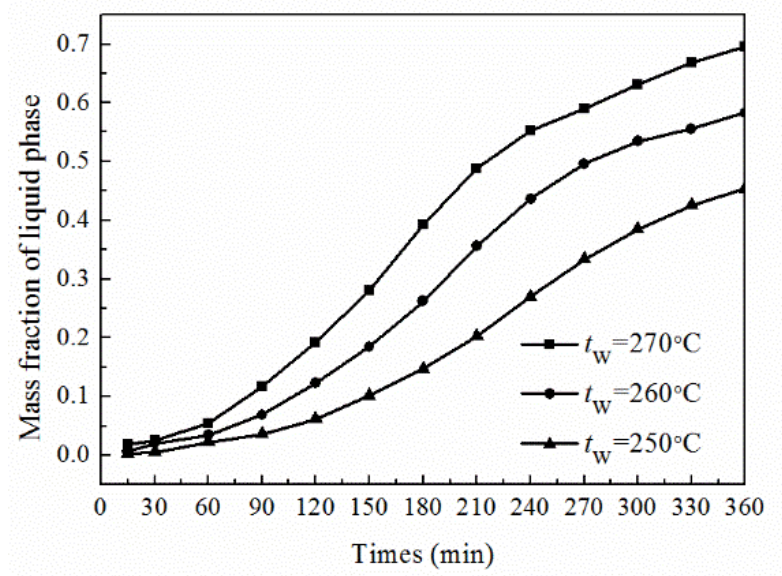

Fig. 6. Mass fraction of liquid phase in the melting process.

From Figs. 5-6, it can be seen that the variation trend of the PCM temperature was coincident, and the velocity of the temperature elevation was gradually decreased since the three temperature differences of the wall was only $10^{\circ} \mathrm{C}$. Therefore, the temperatures in the three conditions were very close with each other. However, it is not obvious that the temperature difference occurred is because the PCM temperature nearly reaches the latent heat temperature before $210 \mathrm{~min}$. The latent heat temperature is relatively steady and the phase changing is the main source to absorb heat in the later period, and hence, the temperature elevation is only a subsidiary. At $360 \mathrm{~min}$, the liquid fraction of the three temperature levels from high to low were $0.696,0.583$ and 0.454 , respectively.

The condition of the heat transfer in the present experiment was further investigated. The heat transfer rate of the thermal wall PCM in the heat transfer area with the computational domain of $8.2 \times 10^{-4} \mathrm{~m}^{2}$, is shown in Fig. 7. It can be seen that the heat transfer rate drastically decreased as the reduction of the difference in heat transfer temperature. The heat transfer rate slowly decreased after $90 \mathrm{~min}$, and the difference of the three boundary conditions kept an obvious level. However, after $210 \mathrm{~min}$, the rate in the wall temperature of $270^{\circ} \mathrm{C}$ was smaller than that of $260^{\circ} \mathrm{C}$. After 26 minutes, 
the heat transfer rate in the wall temperature of $260^{\circ} \mathrm{C}$ was slightly lower than the rate in the wall temperature of $250^{\circ} \mathrm{C}$. This indicates again that the difference in heat transfer temperature was the main influencing factor. However, the temperature variation was associated with the height of the liquid fraction, which is a complex process containing sensible heat and latent heat. However, in the $360 \mathrm{~min}$, the total heat transfer of the three temperature levels were 273.51, 222.48 and 204.92 $\mathrm{MJ} / \mathrm{m}^{2}$, respectively. Taking the liquid fraction rates and total heat transfer into account, in this period, the difference taken by the heat material in the temperatures of $250^{\circ} \mathrm{C}$ and $260^{\circ} \mathrm{C}$ was much lower, and the difference taken by the heat material in the temperatures of $260{ }^{\circ} \mathrm{C}$ and $270{ }^{\circ} \mathrm{C}$ was more obvious.

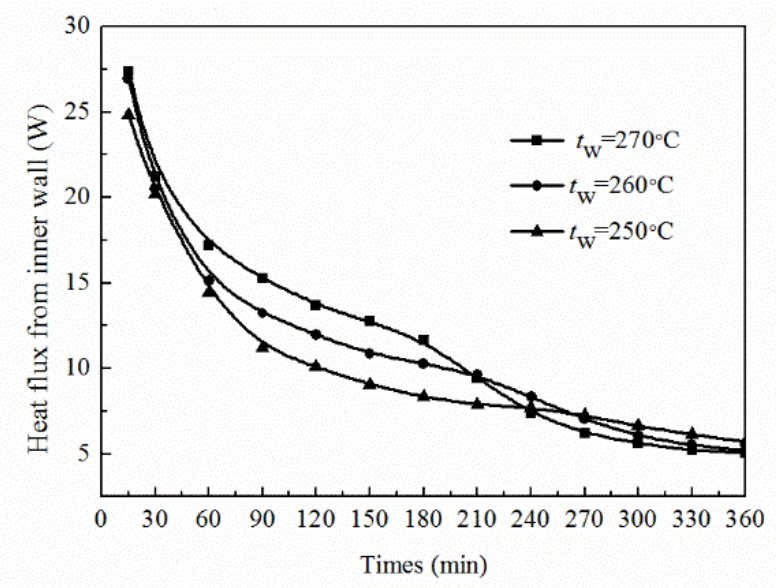

Fig. 7. Heat transfer flux variation from inner wall in the melting process.

On the basis that known conditions are heat transfer area, heat transfer rate and average heat transfer temperature difference, total heat transfer coefficient $K$ can be elicited according to Eq. (3). The variation of $K$ with time is shown in Fig. 8, which can reflect the heat resistance of the PCM to some extent. Visibly, the total heat transfer coefficient decreased slowly at the beginning, and then rose up and drop down for twice. The variation curves with this trend may due to that the temperature of the PCM close to the inner wall rapidly reached the latent heat temperature, while limited liquid molten salt was produced in the outer wall, resulting in solid in the liquid periphery to disable the liquid flowing. Moreover, the thermal conductivity of liquid PCM was 33.33\% lower than that of solid PCM, which caused $R_{1}$ to increase and $K$ to decrease slightly. As liquid fraction increases, natural convection began to take shape (as shown $\tau_{1}$ ), and the mechanism of heat transfer was not only conduction, but the combination of natural convection and conduction. The liquid close to the tube inner wall flowed upward to melt the supernatant solid and move up the phase boundary. Thus, the heat transfer rate began to rise fast. However, after reaching the later inflection point $\tau_{2}$, about $40 \%$ of PCM has molten. The liquid molten salt mainly distributed in the upper tube, and the solid in the upper tube almost disappeared. Therefore, the writhing effected by density difference of solid and liquid phase was becoming weak. In the process when the liquid circular flowed along the phase boundary, the temperature decreased gradually, the power of melting reduced continually, and the natural convection transferred from upper tube to nether tube section. Subsequently, the main parameter of the liquid PCM reduced the effect on the conduction, leading to the reduction of the total heat transfer. So the main form of this stage is the liquid thermal conduction. The second inflection point $\tau_{2}$ of $K$ was mainly influenced by the liquid fraction, in the three conditions, the 
rising rate of liquid fraction in the $250^{\circ} \mathrm{C}$ was most slow, therefore, it's most late to get $\tau_{2}$, and the main switching point of two factors is not obvious as when the temperature is $270{ }^{\circ} \mathrm{C}$, when the influence of two factors is almost equal, the curve after reaching $\tau_{2}$ is gentle. The difference between $\tau_{2}$ and $\tau_{1}$ is the grand total time of natural convection, the total time under three temperatures is almost 3 hours.

Previous investigations have shown that natural convection plays an important role in the melting process, therefore, it's necessary to take natural convection into consideration for latent heat systems. It is beneficial to make $\tau_{1}$ start earlier, and the duration of $\tau_{2}$ longer. In the condition when the continuing period was constant, $\tau_{1}$ under the temperature of $270^{\circ} \mathrm{C}$ was one hour earlier than that of the temperature $250^{\circ} \mathrm{C}$. This phenomenon agreed with the qualitative conclusions of classical theories.

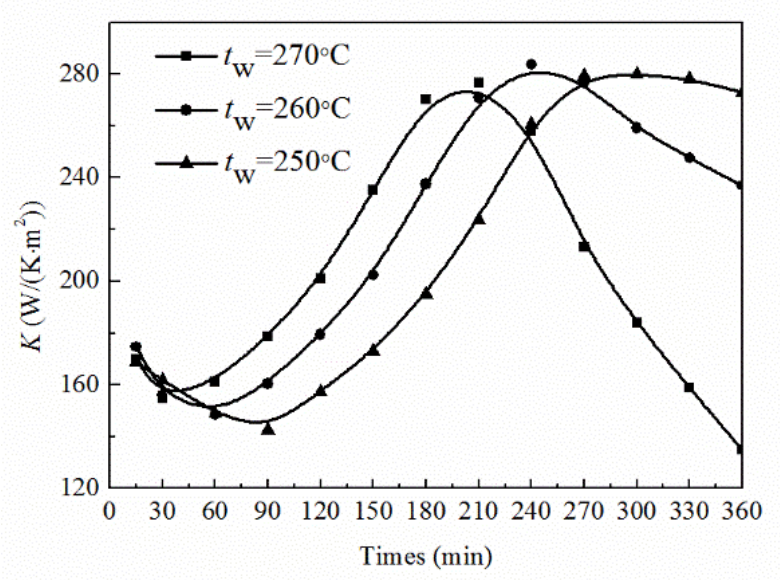

Fig. 8. Total heat transfer coefficient $K$ in the melting process.

Through the comparison of the mass fraction of liquid phase, heat flux, and total heat transfer coefficient variation within $360 \mathrm{~min}$, it was found that rising the heat source temperature by $10 \%$ can result in an obvious difference that the heat source temperature is $20^{\circ} \mathrm{C}$ higher than the phase transition temperature. Therefore, it is better to rise the tube wall temperature as much as possible to achieve more effective heat transfer.

\subsubsection{The second boundary condition}

To compare with the first boundary condition, constant heat flux which has the same total heat transfer of thermal material in the constant wall temperature of $270{ }^{\circ} \mathrm{C}$ in $360 \mathrm{~min}$ (the period of high radiation in one day) was selected as $\mathrm{C}_{2}$ in the second boundary (i.e. heat flux $q_{w}=13.208 \mathrm{KW} / \mathrm{m}^{2}$ ). From numerical simulation, the temperature, liquid fraction and the variation of total heat transfer can be obtained and the results are shown in Figs. 9-12.

Since the total heat transfer in 360 minutes under the first boundary condition was the same as that of the second, the final temperatures of the first and the second were very close. It can be seen that both of the temperatures of HTF and PCM increased tardily in the condition of the constant heat flux, and the temperature difference always stabilized at a small range, and the temperature of 
HTF over $270{ }^{\circ} \mathrm{C}$ was reached until the final $60 \mathrm{~min}$. The temperature and the accumulated total heat transfer of the PCM in the heat storage process were increased slowly in the constant heat flux. However, in the condition of the constant wall temperature, both temperature and the total heat transfer emerged a trend that is slower growth. For the liquid fraction of the PCM, in the first half the fraction was 0 in the condition of constant heat flux, indicating a process of accumulating sensible heat. When the HTF temperature raised, the tin temperature was higher than that in the condition of constant wall temperature. Apart from $180 \mathrm{~min}$, the PCM began to melt gradually and the natural convection began to form. The natural convection was only 130 minutes, which was far lower than 180 minutes in the condition of the constant wall at $270{ }^{\circ} \mathrm{C}$.

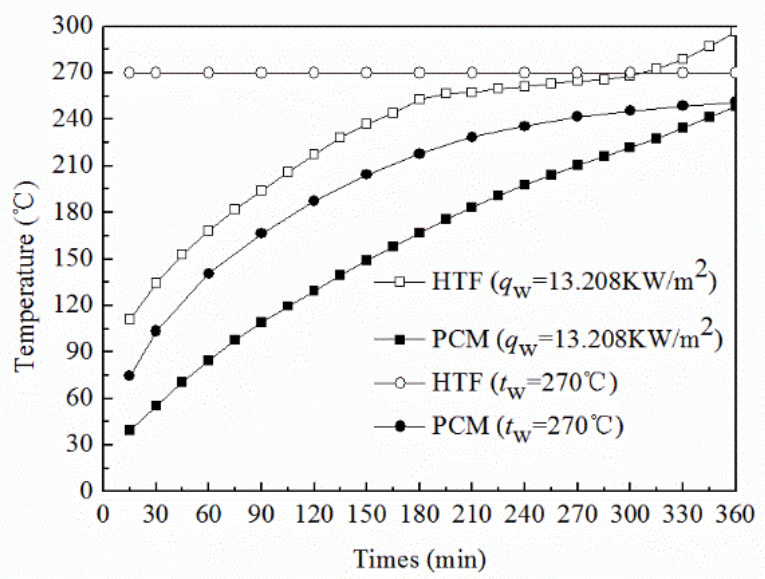

Fig. 9. Average temperature of HTF and PCM in the melting process.

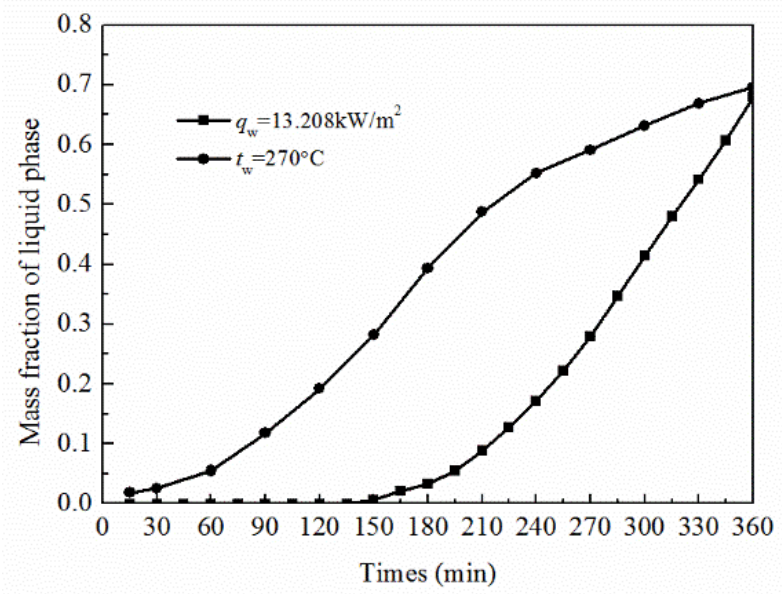

Fig. 10. Mass fraction of liquid phase in melting process. 


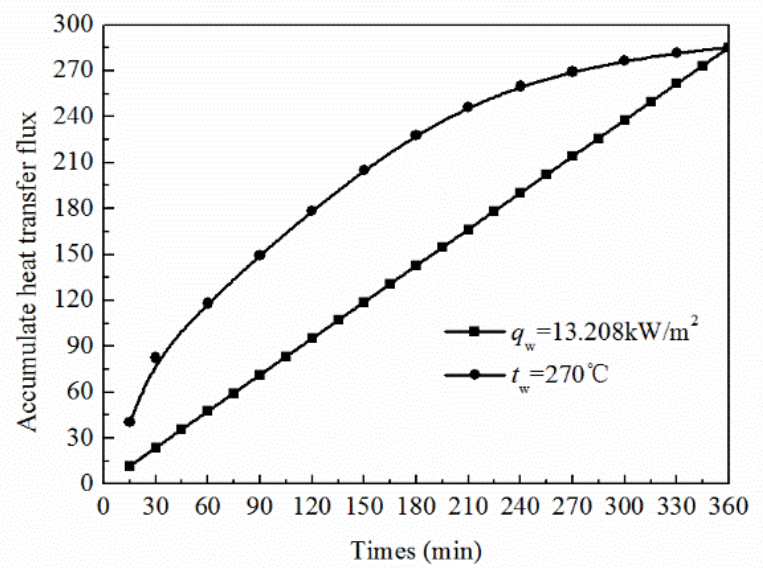

Fig. 11. Accumulated heat transfer flux in the melting process.

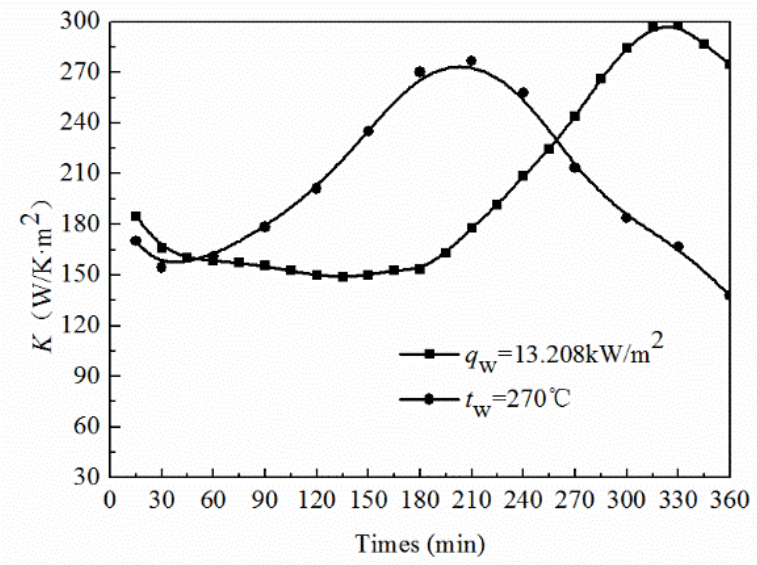

Fig. 12. Total heat transfer coefficient in the melting process.

\subsubsection{The boundary condition of actual solar radiation}

In the actual production process, the quantity of heat contained in the thermal working substance is the heat storage thermal source. Without ministrant thermal source, the of the heat storage the HTF temperature rises gradually because of the constant wall temperature boundary. Ignoring the temperature difference at the entrance, the HTF temperature at the entrance and exit can be considered as constant; this means that the coupling influence of heat storage to the heat collector entrance temperature can be ignored. Therefore, only the single influence of heat collector on heat storage needs to be considered. The solar radiation of Kunming region in a common day was taken as a heat collector thermal source condition (see in Fig. 13), the temperature variation of the HTF can be calculated under the obtained characteristics of the parabolic trough solar concentrated collector, as shown in Fig.14. 


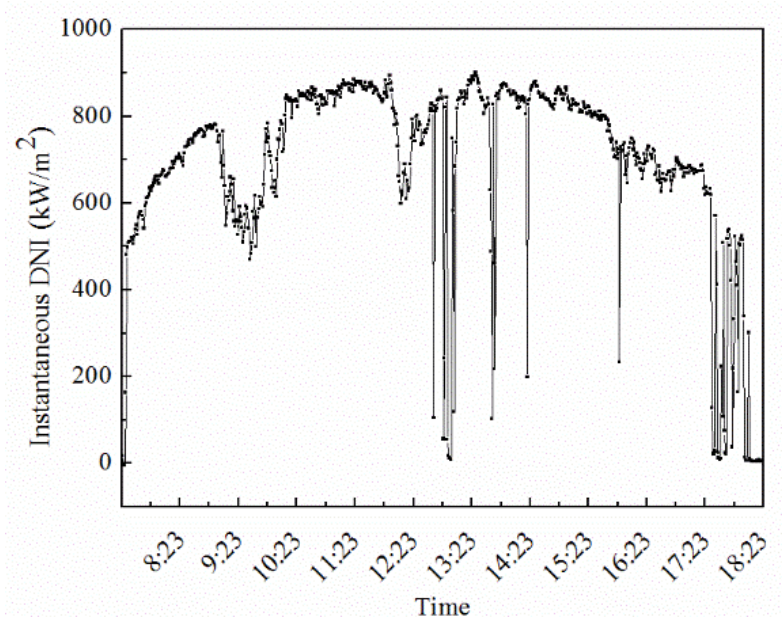

Fig. 13. DNI in Kunming district on May 14, 2016.

It can be seen from Fig. 13 that solar radiation was a parabola gong downwards after sunrise and before sunset, and solar radiation rapidly rose to $500 \mathrm{~kW} / \mathrm{m}^{2}$ at the beginning of sunrise and then decreased slowly. What need to consider is that the solar radiation was not keeping a strict parabola and is influenced by clouds covering.

Based on the previous results in [147], a relationship between the working substance temperature and heat transfer efficiency can be obtained in Fig. 14. According to the relation of energy and temperature rising and set solar radiation as a basis, fitting thermal boundary temperature can be calculated. The longest period of $360 \mathrm{~min}$ is set as constant, some parts truncated from working substance temperature are set as thermal boundary conditions in the numerical simulation, and the liner fit boundary formula is $t_{w}=115.7+0.426 \tau\left({ }^{\circ} \mathrm{C}\right)$. HTF and tube inside wall conducted heat by convection, and the tube inside wall temperature was calculated in the condition of convection. Since heat resistant was low, the temperature difference between tube inside wall and HTF was only about $2{ }^{\circ} \mathrm{C}$, which was considered as assumption (3) under the simulation. Fig. 1517 shows the boundary conditions of the heat storage.

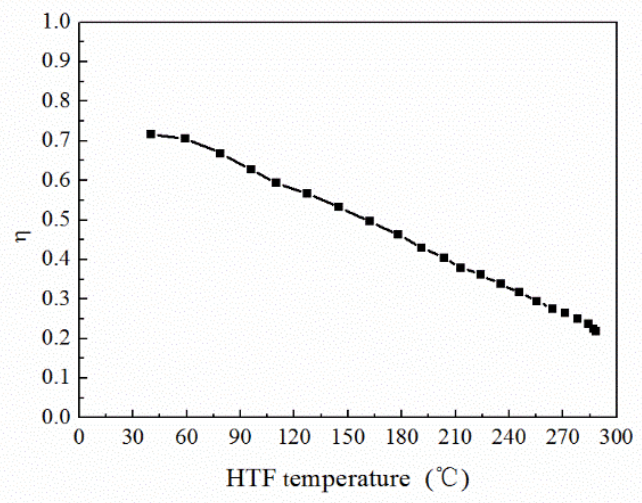

Fig. 14. The relationship between total efficiency $\eta$ and HTF temperature. 

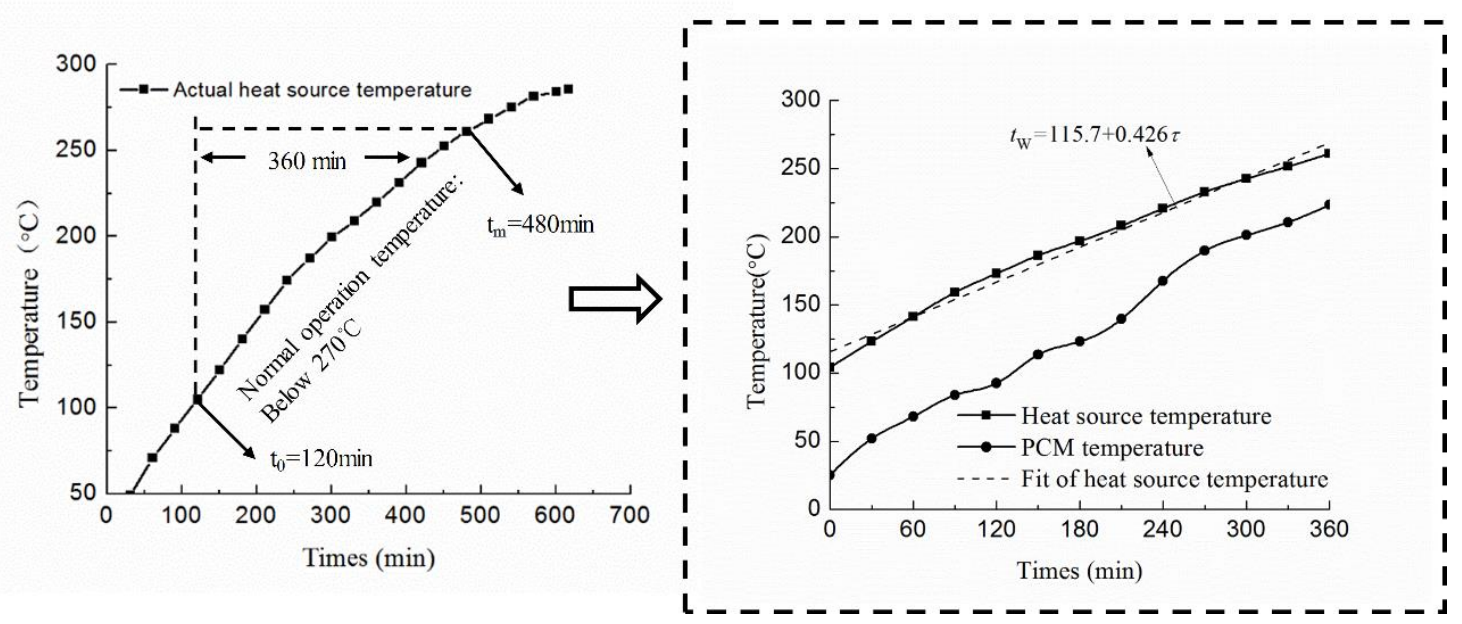

Fig. 15. Average temperature variation of heat resource and PCM in the melting process.

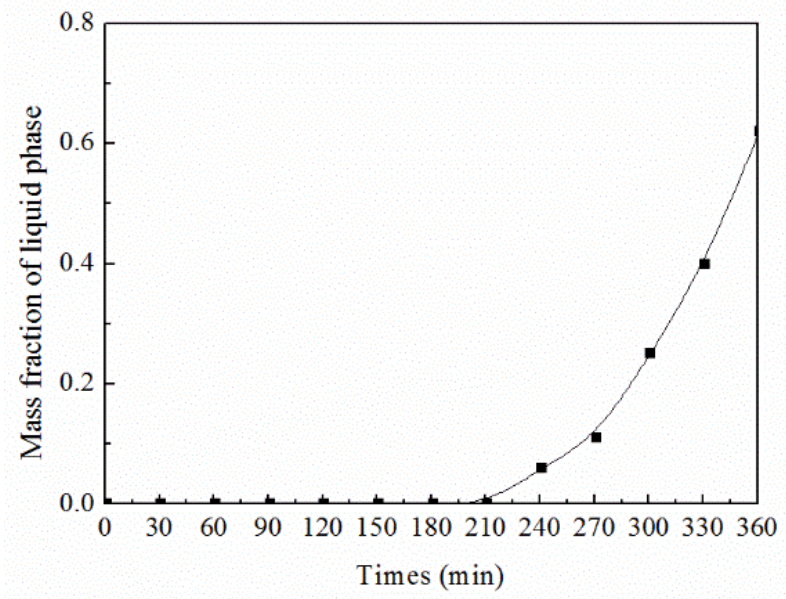

Fig. 16. Mass fraction of liquid phase under actual solar-driven heat source.

It can be seen that the temperature variation of the heat collection material increased in a linear trend. The liquid fraction kept on 0 in the first $210 \mathrm{~min}$ and then increased until to 0.62 . It can see from Fig. 17 that the heat transfer ratio was decreased with small variations.

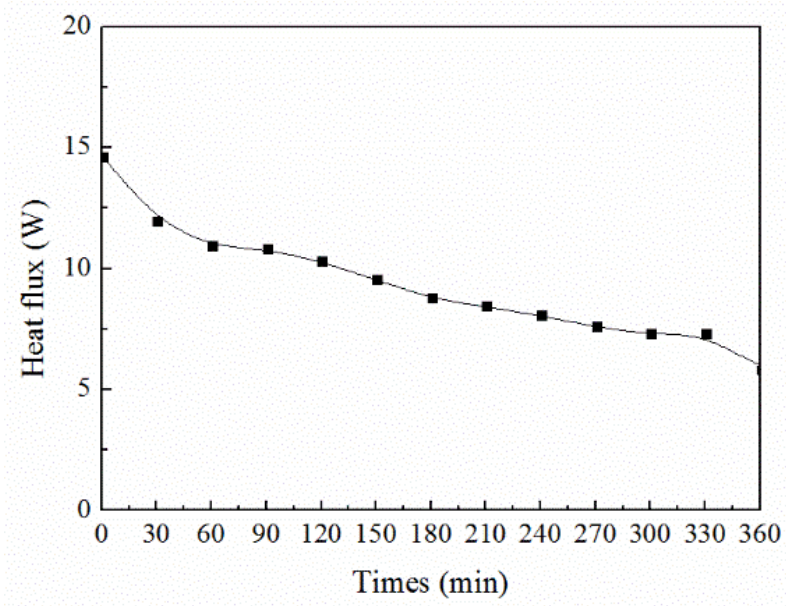

Fig. 17. Heat transfer flux under actual solar-driven heat source. 


\subsection{The comparison among the effect of three boundary conditions to thermal performance}

By focusing on the two boundary conditions given in above, then simulation results of relative parameters were obtained. According to the parameter defined in the reference [148], the heat storage, heat loss and heat storage efficiency were calculated, and the results are summarized in Table 3.

It can be seen that the heat storage efficiency of the first boundary condition in different periods was decreased. However, when the temperature boundary is discrepant, the heat storage efficiency basically kept stable and the heat was $62.13 \%$ of the total heat reserved in $360 \mathrm{~min}$. The temperature of the PCM at this moment was lower than that at the melting point. The total heat transfer of the second boundary condition in $360 \mathrm{~min}$ was the same as the first boundary condition at the $270{ }^{\circ} \mathrm{C}$. However, the heat loss was lower in the whole heat transfer process, and the efficiency was relatively higher. The heat storage efficiency in different period slightly decreased. In addition, in the condition of lower temperature, heat storage at the previous stage was little lower, and the heat transfer variation increased significantly as the increase in the temperature of heat storage. However, there was not an equal relationship between the solar radiation condition and the two boundary conditions.

Table 3 Comparison of heat storage efficiency

\begin{tabular}{|c|c|c|c|c|c|c|}
\hline Heat boundary & $\begin{array}{l}\mathrm{Q}_{360 \mathrm{~min}} \\
(\mathrm{MJ})\end{array}$ & $\begin{array}{l}\mathrm{L}_{360 \text { min }} \\
(\mathrm{MJ})\end{array}$ & $\eta_{360 \mathrm{~min}}$ & $\begin{array}{l}Q_{330 \min } \\
(\mathrm{MJ})\end{array}$ & $\begin{array}{l}\mathrm{L}_{330 \min } \\
(\mathrm{MJ})\end{array}$ & $\eta_{330 \mathrm{~min}}$ \\
\hline$t_{\mathrm{w}}=270^{\circ} \mathrm{C}$ & 10.68 & 2.007 & 0.842 & 10.55 & 1.787 & 0.855 \\
\hline$t_{\mathrm{w}}=260^{\circ} \mathrm{C}$ & 9.92 & 1.881 & 0.841 & 9.745 & 1.676 & 0.853 \\
\hline$t_{\mathrm{w}}=250^{\circ} \mathrm{C}$ & 9.13 & 1.777 & 0.837 & 8.997 & 1.582 & 0.850 \\
\hline $\begin{array}{l}\text { Constant heat } \\
\text { flux }\end{array}$ & 10.680 & 1.439 & 0.881 & 9.749 & 1.22 & 0.889 \\
\hline Solar driven & 9.544 & 1.077 & 0.899 & 8.315 & 0.884 & 0.904 \\
\hline Heat boundary & $\begin{array}{l}\mathrm{Q}_{240 \min } \\
(\mathrm{MJ})\end{array}$ & $\begin{array}{l}\mathrm{L}_{240 \min } \\
(\mathrm{MJ})\end{array}$ & $\eta_{240 \mathrm{~min}}$ & $\begin{array}{l}\mathrm{Q}_{120 \min } \\
(\mathrm{MJ})\end{array}$ & $\begin{array}{l}\mathrm{L}_{120 \text { min }} \\
(\mathrm{MJ})\end{array}$ & $\eta_{120 \min }$ \\
\hline$t_{\mathrm{w}}=270^{\circ} \mathrm{C}$ & 9.822 & 1.124 & 0.897 & 6.636 & 0.367 & 0.948 \\
\hline$t_{\mathrm{w}}=260^{\circ} \mathrm{C}$ & 9.043 & 1.056 & 0.895 & 6.062 & 0.347 & 0.946 \\
\hline$t_{\mathrm{w}}=250^{\circ} \mathrm{C}$ & 8.073 & 0.997 & 0.890 & 5.753 & 0.329 & 0.946 \\
\hline $\begin{array}{l}\text { Constant heat } \\
\text { flux }\end{array}$ & 7.037 & 0.535 & 0.929 & 3.446 & 0.128 & 0.964 \\
\hline Solar driven & 5.354 & 0.397 & 0.931 & 1.785 & 0.055 & 0.970 \\
\hline
\end{tabular}

770

\section{Conclusions}

Based on the development status of solar medium and low temperature thermal utilization systems, this paper introduced the application and performance research on subsystems of the solar system, as well as the matching relationship and the overall dynamic performance. A case with respect to thermal performance of a heat storage driven by different heat collection modes is analyzed. The main conclusions are as follows.

- Solar heat for industrial processes showed a huge potential, which temperature could be 
mainly distributed in $60-250^{\circ} \mathrm{C}$. The PTC is more attractive for medium temperature applications. The single performance of the collector has obtained much attention, however, there are only a few studies considered the heat-collecting storage-utilization as a whole system.

- In the field of thermal energy storage, latent heat storage showed a good potential. The low conductivity of PCMs is an obstacle and many methods have been presented to enhance the heat transfer performance. The analysis of PCM charging and discharging performance was often carried out by numerical simulation, and experiments.

- As for the matching relationship of the subsystems, it is necessary to establish a dynamic model to study the heat transfer characteristics of the heat-collecting and heat-storing coupled system, as well as the heat-utilization coupled system under different temperature.

- The case illustrates that for a coupled solar system, the preferred choice of heat boundary condition in the numerical simulation is measured parameters, and the second choice is the constant heat flux corresponding to the same total heat flux as the actual circumstance.

\section{Acknowledgement}

This work is supported by the National Science Foundation of China (Grant No: 51866005, 51965027); the Scientific Research Project funded by Yunnan Provincial Education Department (No.: 2019J0049); the Technology Plan Project of Yunnan Science, China (Grant No: 2017FB092), Taishan Scholar, China (tsqn201812025) and Australia ARC DECRA (No. DE190100931).

\section{References}

[1] BP. Statistical Review of World Energy [EB/OL]. https://www.bp.com/zh_cn/china /reports-and-publications/_bp_2018_..html, 2018-7-30, Accessed 9-19-2019.

[2] National Energy Administration. The 13th Five-year Plan for Power Development[EB/OL]. http://www.nea.gov.cn/policy/zxwj.htm, Accessed 9-19-2019.

[3] Iparraguirre I, Huidobro A, Fernández-García A, et al. Solar Thermal Collectors for Medium Temperature Applications: A Comprehensive Review and Updated Database[J]. Energy Procedia, 2016, 91:64-71.

[4] Silva R, Pérez M, Fernández-Garcia A. Modeling and co-simulation of a parabolic trough solar plant for industrial process heat[J]. Applied Energy, 2013, 106(106):287-300.

[5] Ritter D, Schmitt B, Vajen K. Solar Heat for Industrial Processes in Germany - Market Overview and Detailed Monitoring of Selected Systems[C]. Ises Solar World Congress. 2016:1-10.

[6] National Bureau of Statistics, PRC. China statistical yearbook 2017, energy. [EB/OL]. http://www.stats.gov.cn/tjsj/ndsj/2017/indexch.htm, Accessed 9-19-2019.

[7] T Jia, J Huang, R Li, et al. Status and prospect of solar heat for industrial processes in China. Renewable and Sustainable Energy Reviews, 2018,90:475-489.

[8] Duffie J A, Beckman W A. Solar Industrial Process Heat[M]. Solar Engineering of Thermal Processes. John Wiley \& Sons, Inc. 2013:604-620.

[9] Naik H, Baredar P, Kumar A. Medium temperature application of concentrated solar thermal technology: Indian perspective. Renewable \& Sustainable Energy Reviews, 2017, 76:369-378.

[10] SH Farjana, N Huda, MAP Mahmud, R Saidur. Solar industrial process heating systems in 
operation-Current SHIP plants and future prospects in Australia[J]. Renewable \& Sustainable Energy Reviews, 2018, 91: 409-419.

[11] World Map of Solar Thermal Plants[EB/OL]. 〈http://ship-plants.info/solar-thermal-plants〉.

[12] Ramos C, Ramirez R, Beltran J. Potential Assessment in Mexico for Solar Process Heat Applications in Food and Textile Industries[J]. Energy Procedia, 2014, 49(20):1879-1884.

[13] Li Q, Zheng C, Shirazi A, et al. Design and analysis of a medium-temperature, concentrated solar thermal collector for air-conditioning applications[J]. Applied Energy, 2017, 190: 1159-1173. [14] Sharma A K, Sharma C, Mullick S C, et al. GHG Mitigation Potential of Solar Industrial Process Heating in Producing Cotton based Textiles in India[J]. Journal of Cleaner Production, 2016, 145: 74-84.

[15] Sharma A K, Sharma C, Mullick S C, et al. Potential of solar industrial process heating in dairy industry in India and consequent carbon mitigation[J]. Journal of Cleaner Production, 2017, 140:714-724.

[16] Silva R, Cabrera F J, Pérez M. Process Heat Generation with Parabolic Trough Collectors for a Vegetables Preservation Industry in Southern Spain[J]. Energy Procedia, 2014, 48(48):1210-1216. [17] Absi Halabi M, Al-Qattan A, Al-Otaibi A. Application of solar energy in the oil industry-Current status and future prospects[J]. Renewable \& Sustainable Energy Reviews, 2015, 43: 296314.

[18] Solar heat worldwide, 2016[EB/OL]. http://www.iea-shc.org/solarshc.org/solar-heat worldwide.

[19] Hansen K, Vad Mathiesen B. Comprehensive assessment of the role and potential for solar thermal in future energy systems[J]. Solar Energy, 2018, 169:144-152.

[20] Behar O, Kazmerski L. Solar thermal power plants - A review of configurations and performance comparison[J]. Renewable \& Sustainable Energy Reviews, 2018, 92: 608-627.

[21] Sharma A K, Sharma C, Mullick S C, et al. Financial viability of solar industrial process heating and cost of carbon mitigation: A case of dairy industry in India[J]. Sustainable Energy Technologies \& Assessments, 2018, 27:1-8.

[22] Raju Ramaiah, K.S. Shashi Shekar. Solar Thermal Energy Utilization for Medium Temperature Industrial Process Heat Applications - A Review[C]. IOP Conference Series: Materials Science and Engineering, 376(1): 012035.

[23] Solar thermal plants database[EB/OL]. 〈http://ship-plants.info/solar-thermal-plants $\rangle.$

[24] Mekhilef S, Saidur R, Safari A. A review on solar energy use in industries[J]. Renewable \& Sustainable Energy Reviews, 2011, 15(4):1777-1790.

[25] IEA/SHC Task49: Integration Guideline[EB/OL]. 〈http://www.solarthermalworld.org/ sites/gstec/files/news/file/2016-02-17/iea_task_49_integration_guideline-february_2015.pdf $\rangle$.

[26] IEA-ETSAP and IRENA Technology Brief E21: solar heat for industrial processes. 2015.01. 〈http://www.irena.org/DocumentDownloads/Publications/IRENA_ETSAP_Tech_Brief_E21_Sola r_Heat_Industrial_2015.pdf $\rangle$.

[27] Farjana S H, Huda N, Mahmud M A P, et al. Solar process heat in industrial systems - A global review[J]. Renewable \& Sustainable Energy Reviews, 2018, 82 (3) : 2270-2286.

[28] Powell K M, Edgar T F. Modeling and control of a solar thermal power plant with thermal energy storage[J]. Chemical Engineering Science, 2012, 71: 138-145.

[29] Khan M M A, Ibrahim N I, Mahbubul I M, et al. Evaluation of solar collector designs with 
integrated latent heat thermal energy storage: A review[J]. Solar Energy, 2018, 166: 334-350.. [30] Bhagyalakshmi P, Rajan K, Kumar K R S. Experimental Study on Solar Energy Storage using Phase Change Materials in Spherical Shell Storage System[J]. Oriental Journal of Chemistry, 2018, 34(1):507-512.

[31] Shire G S F, Moss R W, Henshall P, et al. Development of an Efficient Low- and MediumTemperature Vacuum Flat-Plate Solar Thermal Collector[M]// Renewable Energy in the Service of Mankind Vol II. Springer International Publishing, 2016.

[32] Pandey K M, Chaurasiya R. A review on analysis and development of solar flat plate collector[J]. Renewable \& Sustainable Energy Reviews, 2017, 67:641-650.

[33] Muhammad M J, Muhammad I A, Sidik N A C. Thermal performance enhancement of flatplate and evacuated tube solar collectors using nanofluid: A review[J]. International Communications in Heat \& Mass Transfer, 2016, 76:6-15.

[34] Foeste S, Giovannetti F, Ehrmann N, Rockendorf G. Performance and reliability of a high efficiency flat plate collector - final results on prototypes[J]. Energy Procedia.2014,48:48-57.

[35] Beikircher T, Osgyan P, Reuss M, Streib G. Flat plate collector for process heat with full surface aluminium absorber, vacuum super insulation and front foil[J]. Energy Procedia 2014, 48:9-17. [36] Iranmanesh S, Chyuan O H, Ang B C, et al. Thermal performance enhancement of an evacuated tube solar collector using graphene nanoplatelets nanofluid[J]. Journal of Cleaner Production, 2017 , 162: 121-129.

[37] IEA/SHC Task49: process heat collectors: state of the art and available medium temperature collectors[EB/OL]. http://task49.iea-shc.org/publications

[38] Kalogirou S. The potential of solar industrial process heat applications[J]. Applied Energy, 2003, 76(4):337-361.

[39] Kalogirou S A. Parabolic trough collectors for industrial process heat in Cyprus[J]. Energy, 2002, 27(9):813-830.

[40] Mahesh A. Solar collectors and adsorption materials aspects of cooling system[J]. Renewable \& Sustainable Energy Reviews, 2017, 73:1300-1312.

[41] Kramer K. Interaction of regulation and innovation: solar air heating collectors[J]. Energy Procedia, 2015, 30:1311-1330.

[42] Colangelo G, Favale E, Miglietta P, Risi A. Innovation in flat solar thermal collectors: a review of the last ten years experimental results[J]. Renewable \& Sustainable Energy Reviews, 2016,57:1141-1159.

[43] Jiyun Qin, Eric Hu, Xiaohua Li. Solar aided power generation: A review[J]. Energy and Built Environment, 2020, 1(1):11-26.

[44] Abdelaziz E A, Saidur R, Mekhilef S. A review on energy saving strategies in industrial sector[J]. Renewable \& Sustainable Energy Reviews, 2011, 15(1):150-168.

[45] Benoit H, Spreafico L, Gauthier D, et al. Review of heat transfer fluids in tube-receivers used in concentrating solar thermal systems: Properties and heat transfer coefficients[J]. Renewable \& Sustainable Energy Reviews, 2016, 55:298-315.

[46] Bellas D V, Lidorikis E. Design of high-temperature solar-selective coatings for application in solar collectors[J]. Solar Energy Materials \& Solar Cells, 2017, 170:102-113.

[47] Mohan G, Kumar U, Pokhrel M K, et al. A novel solar thermal polygeneration system for sustainable production of cooling, clean water and domestic hot water in United Arab Emirates: Dynamic simulation and economic evaluation. Applied Energy, 2016, 167:173-188. 
[48] Conrado L S, Rodriguez-Pulido A, Calderón G. Thermal performance of parabolic trough solar collectors. Renewable \& Sustainable Energy Reviews, 2017, 67:1345-1359.

[49] Nation D D, Heggs P J, Dixon-Hardy D W. Modelling and simulation of a novel Electrical Energy Storage (EES) Receiver for Solar Parabolic Trough Collector (PTC) power plants. Applied Energy, 2017, 195:950-973.

[50] Özgür Bayer, Uzgoren E. Comparison of dynamic PTC thermal models using semi-analytical and finite volume methods. Environmental Progress \& Sustainable Energy, 2017, 37(3): 1191-1200. [51] Zou B, Dong J, Yao Y, et al. An experimental investigation on a small-sized parabolic trough solar collector for water heating in cold areas. Applied Energy, 2016, 163:396-407.

[52] Kumaresan G, Sudhakar P, Santosh R, et al. Experimental and numerical studies of thermal performance enhancement in the receiver part of solar parabolic trough collectors. Renewable \& Sustainable Energy Reviews, 2017, 77: 1363-1374.

[53] Sharma A K, Sharma C, Mullick S C, et al. Solar industrial process heating: A review. Renewable \& Sustainable Energy Reviews, 2017, 78:124-137.

[54] Fernández-García A, Rojas E, Pérez M, et al. A parabolic-trough collector for cleaner industrial process heat[J]. Journal of Cleaner Production, 2015, 89:272-285.

[55] Ghritlahre H K, Prasad R K. Application of ANN technique to predict the performance of solar collector systems -A review[J]. Renewable \& Sustainable Energy Reviews, 2018, 84:75-88.

[56] Yang S, Sensoy T, Ordonez J C. Dynamic 3D volume element model of a parabolic trough solar collector for simulation and optimization[J]. Applied Energy, 2018, 217:509-526.

[57] Gong X, Wang F, Wang H, et al. Heat transfer enhancement analysis of tube receiver for parabolic trough solar collector with pin fin arrays inserting[J]. Solar Energy, 2017, 144:185-202.

[58] Bellos E, Tzivanidis C, Tsimpoukis D. Multi-criteria evaluation of parabolic trough collector with internally finned absorbers[J]. Applied Energy, 2017, 205:540-561.

[59] Wang K, He YL, Xue XD, Du BC. Multi-objective optimization of the aiming strategy for the solar power tower with a cavity receiver by using the non-dominated sorting genetic algorithm[J]. Applied Energy, 2017, 205: 399-416.

[60] Cohen S, Grossman G. Development of a solar collector with a stationary spherical reflector/tracking absorber for industrial process heat[J]. Solar Energy, 2016,128:31-40.

[61] Alva G, Lin Y, Fang G. An overview of thermal energy storage systems[J]. Energy, 2018, 144:341-378.

[62] Sharma A, Tyagi V V, Chen C R, et al. Review on thermal energy storage with phase change material and applications[J]. Renewable \& Sustainable Energy Reviews, 2009, 13(2):318-345.

[63] Agyenim F, Hewitt N, Eames P, et al. A review of materials, heat transfer and phase change problem formulation for latent heat thermal energy storage systems (LHTESS)[J]. Renewable \& Sustainable Energy Reviews, 2010, 14(2):615-628.

[64] Xie B, Li C, Zhang B, et al. Evaluation of stearic acid/coconut shell charcoal composite phase change thermal energy storage materials for tankless solar water heater[J]. Energy and Built Environment, 2019, https://doi.org/10.1016/j.enbenv.2019.08.003.

[65] Liu M, Tay N H S, Bell S, et al. Review on concentrating solar power plants and new developments in high temperature thermal energy storage technologies[J]. Renewable \& Sustainable Energy Reviews, 2016, 53:1411-1432.

[66] Miró L, Gasia J, Cabeza L F. Thermal energy storage (TES) for industrial waste heat (IWH) recovery: A review[J]. Applied Energy, 2016, 179:284-301. 
[67] Cabeza L F, Sole C, Castell A, et al. Review of solar thermal storage techniques and associated heat transfer technologies[J]. Proceedings of the IEEE, 2012, 100(2): 525-538.

[68] Bauer T, Pfleger N, Breidenbach N, et al. Material aspects of Solar Salt for sensible heat storage[J]. Applied Energy, 2013, 111:1114-1119.

[69] Li X, Xu E, Song S, et al. Dynamic simulation of two-tank indirect thermal energy storage system with molten salt[J]. Renewable Energy, 2017, 113: 1311-1319.

[70] Zaversky F, Asiain J P D Z, Sánchez M. Transient response simulation of a passive sensible heat storage system and the comparison to a conventional active indirect two-tank unit[J]. Energy, 2017, 139: 782-797.

[71] Flueckiger S M, Garimella S V. Latent heat augmentation of thermocline energy storage for concentrating solar power - A system-level assessment[J]. Applied Energy, 2014, 116(3):278-287.

[72] Kim J K, Yoon H K, Kang Y H, et al. Solar thermal power generation system using single hot molten salt thermal energy storage tank: U.S. Patent 9,651,030[P]. 2017-5-16.

[73] Zhang M, Xu C, Du X, et al. Off-design performance of concentrated solar heat and coal double-source boiler power generation with thermocline energy storage[J]. Applied Energy, 2017 , 189:697-710.

[74] Akhmetov B, Seitov A, Popov R et al. Experimental and numerical studies of PCM-based storage for solar thermal energy storage applications[J]. Journal of Mathematics, Mechanics and Computer Science, 2018, 93(1): 55-68

[75] Fan L, Khodadadi J M. Thermal conductivity enhancement of phase change materials for thermal energy storage: A review $\dot{s}[\mathrm{~J}]$. Renewable \& Sustainable Energy Reviews, 2016, 62(1):305-317.

[76] Alva G, Liu L, Huang X, et al. Thermal energy storage materials and systems for solar energy applications[J]. Renewable \& Sustainable Energy Reviews, 2017, 68:693-706.

[77] Tay N H S, Liu M, Belusko M, et al. Review on transportable phase change material in thermal energy storage systems[J]. Renewable \& Sustainable Energy Reviews, 2016, 75: 264-277.

[78] Vasu A, Hagos F Y, Noor M M, et al. Corrosion effect of phase change materials in solar thermal energy storage application[J]. Renewable \& Sustainable Energy Reviews, 2017, 76:19-33.

[79] Wei G, Wang G, Xu C, et al. Selection principles and thermophysical properties of high temperature phase change materials for thermal energy storage: A review[J]. Renewable \& Sustainable Energy Reviews, 2018, 81:1771-1786.

[80] Trabelsi S E, Qoaider L, Guizani A. Investigation of using molten salt as heat transfer fluid for dry cooled solar parabolic trough power plants under desert conditions[J]. Energy Conversion \& Management, 2018, 156:253-263.

[81] Zhang P, Ma F, Xiao X. Thermal energy storage and retrieval characteristics of a molten-salt latent heat thermal energy storage system[J]. Applied Energy, 2016, 173:255-271.

[82] Pfleger N, Bauer T, Martin C, et al. Thermal energy storage - overview and specific insight into nitrate salts for sensible and latent heat storage[J]. Beilstein Journal of Nanotechnology, 2015, 6(1):1487-1497.

[83] Jin Y, Cheng J, An X, et al. Accurate viscosity measurement of nitrates/nitrites salts for concentrated solar power[J]. Solar Energy, 2016, 137:385-392.

[84] Raade J, Vaughn J, Elkin B. Thermal energy storage with molten salt: WO, 2013116510 A1[P]. 2013.

[85] Tian H, Du L, Huang C, et al. Enhanced Specific Heat of Chloride Salt with Mg Particles for 
High-temperature Thermal Energy Storage $\lesssim[\mathrm{J}]$. Energy Procedia, 2017, 105:4402-4407.

[86] Zhou D, Eames P. A study of a eutectic salt of lithium nitrate and sodium chloride (87-13\%) for latent heat storage[J]. Solar Energy Materials \& Solar Cells, 2017, 167:157-161.

[87] Zhou D, Eames P. Thermal characterisation of binary sodium/lithium nitrate salts for latent heat storage at medium temperatures[J]. Solar Energy Materials \& Solar Cells, 2016, 157:1019-1025. [88] Cunha J P D, Eames P. Thermal energy storage for low and medium temperature applications using phase change materials - A review[J]. Applied Energy, 2016, 177:227-238.

[89] Bradshaw R W, Brosseau D A. Low-melting point inorganic nitrate salt heat transfer fluid: US, US7588694[P]. 2009.

[90] Ren N, Wu Y T, Wang T, et al. Experimental study on optimized composition of mixed carbonate for phase change thermal storage in solar thermal power plant[J]. Journal of Thermal Analysis \& Calorimetry, 2011, 104(3):1201-1208.

[91] Bradshaw R W, DAWSON D B, DE LA ROSA W, et al. Final test and evaluation results from the solar two project[R]. Sandia National Labs., Albuquerque, NM (US); Sandia National Labs., Livermore, CA (US), 2002.

[92] Ruegamer T, Kamp H, Kuckelkorn T, et al. Molten Salt for Parabolic Trough Applications: System Simulation and Scale Effects[J]. Energy Procedia, 2014, 49:1523-1532.

[93] Jacob R, Belusko M, Fernández A I, et al. Embodied energy and cost of high temperature thermal energy storage systems for use with concentrated solar power plants[J]. Applied Energy, 2016, 180:586-597.

[94] Fernandez A I, Martínez M, Segarra M, et al. Selection of materials with potential in sensible thermal energy storage[J]. Solar Energy Materials \& Solar Cells, 2010, 94(10):1723-1729.

[95] Pointner H, Gracia A D, Vogel J, et al. Computational efficiency in numerical modeling of high temperature latent heat storage: Comparison of selected software tools based on experimental data[J]. Applied Energy, 2016, 161:337-348.

[96] Tao Y B, He Y L. A review of phase change material and performance enhancement method for latent heat storage system[J]. Renewable \& Sustainable Energy Reviews, 2018, 93:245-259.

[97] Al-Maghalseh M, Mahkamov K. Methods of heat transfer intensification in PCM thermal storage systems: Review paper[J]. Renewable \& Sustainable Energy Reviews, 2018, 92:62-94.

[98] Nomura T, Sheng N, Zhu C, et al. Microencapsulated phase change materials with high heat capacity and high cyclic durability for high-temperature thermal energy storage and transportation[J]. Applied Energy, 2017, 188:9-18.

[99] Zhang L, Yang W, Jiang Z, et al. Graphene oxide-modified microencapsulated phase change materials with high encapsulation capacity and enhanced leakage-prevention performance[J]. Applied Energy, 2017, 197: 354-363.

[100] Li M J, Jin B, Ma Z, et al. Experimental and numerical study on the performance of a new high-temperature packed-bed thermal energy storage system with macro encapsulation of molten salt phase change material[J]. Applied Energy, 2018, 221:1-15.

[101] Liu L, Su D, Tang Y, et al. Thermal conductivity enhancement of phase change materials for thermal energy storage: A review[J]. Renewable and Sustainable Energy Reviews, 2016, 62: $305-$ 317.

[102] Karaipekli A, Biçer A, Sarı A, et al. Thermal characteristics of expanded perlite/paraffin composite phase change material with enhanced thermal conductivity using carbon nanotubes[J]. Energy Conversion and Management, 2017, 134: 373-381. 
[103] Fukai J, Kanou M, Kodama Y, et al. Thermal conductivity enhancement of energy storage media using carbon fibers[J]. Energy Conversion and Management, 2000, 41(14):1543-1556.

[104] Frusteri F, Leonardi V, Vasta S, et al. Thermal conductivity measurement of a PCM based storage system containing carbon fibers[J]. Applied Thermal Engineering, 2005, 25(11): 1623-1633. [105] Meng Z N, Zhang P. Experimental and numerical investigation of a tube-in-tank latent thermal energy storage unit using composite PCM[J]. Applied Energy, 2017, 190: 524-539.

[106] Mettawee E B S, Assassa G M R. Thermal conductivity enhancement in a latent heat storage system[J]. Solar Energy, 2007, 81(7): 839-845.

[107] Sciacovelli A, Colella F, Verda V. Melting of PCM in a thermal energy storage unit: Numerical investigation and effect of nanoparticle enhancement[J]. International Journal of Energy Research, 2013, 37(13):1610-1623.

[108] Fan L W, Fang X, Wang X, et al. Effects of various carbon nanofillers on the thermal conductivity and energy storage properties of paraffin-based nanocomposite phase change materials[J]. Applied Energy, 2013, 110: 163-172.

[109] Das N, Kohno M, Takata Y, et al. Enhanced melting behavior of carbon based phase change nanocomposites in horizontally oriented latent heat thermal energy storage system[J]. Applied Thermal Engineering, 2017, 125: 880-890.

[110] Das N, Takata Y, Kohno M, et al. Effect of carbon nano inclusion dimensionality on the melting of phase change nanocomposites in vertical shell-tube thermal energy storage unit[J]. International Journal of Heat and Mass Transfer, 2017, 113: 423-431.

[111] Xiao X, Zhang P. Numerical and experimental study of heat transfer characteristics of a shelltube latent heat storage system: Part I-Charging process[J]. Energy, 2015, 79: 337-350.

[112] Wang T, Wang S, Geng L, et al. Enhancement on thermal properties of paraffin/calcium carbonate phase change microcapsules with carbon network[J]. Applied Energy, 2016, 179: 601608.

[113] Li B, Zhai X. Experimental investigation and theoretical analysis on a mid-temperature solar collector/storage system with composite PCM[J]. Applied Thermal Engineering, 2017, 124:34-43.

[114] Ibrahim N I, Al-Sulaiman F A, Rahman S, et al. Heat transfer enhancement of phase change materials for thermal energy storage applications: A critical review[J]. Renewable \& Sustainable Energy Reviews, 2017, 74:26-50.

[115] Merlin K, Delaunay D, Soto J, et al. Heat transfer enhancement in latent heat thermal storage systems: Comparative study of different solutions and thermal contact investigation between the exchanger and the PCM[J]. Applied Energy, 2016, 166:107-116.

[116] Chang C, Sciacovelli A, Wu Z, et al. Enhanced heat transfer in a parabolic trough solar receiver by inserting rods and using molten salt as heat transfer fluid[J]. Applied Energy, 2018, 220:337-350.

[117] Sandeep H M, Arunachala U C. Solar parabolic trough collectors: A review on heat transfer augmentation techniques[J]. Renewable \& Sustainable Energy Reviews, 2016, 69(C):1218-1231. [118] Ogoh W, Groulx D. Effects of the number and distribution of fins on the storage characteristics of a cylindrical latent heat energy storage system: a numerical study[J]. Heat \& Mass Transfer, 2012, 48(10):1825-1835.

[119] Liu Z, Yao Y, Wu H. Numerical modeling for solid-liquid phase change phenomena in porous media: Shell-and-tube type latent heat thermal energy storage[J]. Applied Energy, 2013, 112(16):1222-1232.

[120] Al-Abidi A A, Mat S, Sopian K, et al. Internal and external fin heat transfer enhancement 
technique for latent heat thermal energy storage in triplex tube heat exchangers[J]. Applied Thermal Engineering, 2013, 53(1):147-156.

[121] Mat S, Al-Abidi A A, Sopian K, et al. Enhance heat transfer for PCM melting in triplex tube with internal-external fins[J]. Energy Conversion \& Management, 2013, 74(5):223-236.

[122] Pizzolato A, Sharma A, Maute K, et al. Design of effective fins for fast PCM melting and solidification in shell-and-tube latent heat thermal energy storage through topology optimization[J]. Applied Energy, 2017, 208: 210-227.

[123] Yang X, Lu Z, Bai Q, et al. Thermal performance of a shell-and-tube latent heat thermal energy storage unit: Role of annular fins[J]. Applied energy, 2017, 202: 558-570.

[124] Shinde A, Arpit S, Pramod K M, et al. Heat Transfer Characterization and Optimization of Latent Heat Thermal Storage System Using Fins for Medium Temperature Solar Applications[J]. Journal of Solar Energy Engineering, 2017, 139:031003-1-031003-10.

[125] Veeraragavan A, Pei W S, Veeraragavan A, et al. Modeling of Heat Losses from a PCM Storage Tank for Solar Thermophotovoltaic Systems[J]. Journal of Energy Engineering, 2017, 143(5) : 04017033.

[126] G. Senthil Kumar, D. Nagarajan, L.A. Chidambaram, V. Kumaresan, Y. Ding, R. Velraj. Role of PCM addition on stratification behaviour in a thermal storage tank - An experimental study[J] Energy, 2016,115: 1168-1178.

[127] Bouhal T, Fertahi S, Agrouaz Y, et al. Numerical modeling and optimization of thermal stratification in solar hot water storage tanks for domestic applications: CFD study[J]. Solar Energy, 2017, 157:441-455.

[128] Wang Z, Zhang H, Dou B, et al. Experimental and numerical research of thermal stratification with a novel inlet in a dynamic hot water storage tank[J]. Renewable Energy, 2017, 111:353-371.

[129] Moncho-Esteve I J, Gasque M, González-Altozano P, et al. Simple inlet devices and their influence on thermal stratification in a hot water storage tank[J]. Energy \& Buildings, 2017, 150: 625-638.

[130] Baghernejad A, Yaghoubi M. Thermoeconomic Methodology for Analysis and Optimization of a Hybrid Solar Thermal Power Plant[J]. International Journal of Green Energy, 2013, 10(6):588609.

[131] Mohamadi Z M, Zohoor H. Introducing a dimensionless number as tank selector in hybrid solar thermal energy storage systems[J]. Journal of Mechanical Science \& Technology, 2011, 25(4):871-876.

[132] Heller L, Gauché P. Modeling of the rock bed thermal energy storage system of a combined cycle solar thermal power plant in South Africa[J]. Solar Energy, 2013, 93(7):345-356.

[133] Zhao Y, Hong H, Jin H, et al. Thermodynamic Mechanism for Hybridization of Moderatetemperature Solar Heat with Conventional Fossil-Fired Power Plant[J]. Energy, 2017, 133: 832-842. [134] Menéndez R P, Martínez J A, Prieto M J, et al. A Novel Modeling of Molten-Salt Heat Storage Systems in Thermal Solar Power Plants[J]. Energies, 2014, 7(10):6721-6740.

[135] Zhao J, Ji Y, Yuan Y, et al. Seven Operation Modes and Simulation Models of Solar Heating System with PCM Storage Tank[J]. Energies, 2017, 10(12): 2128-2139.

[136] Li Q, Bai F, Yang B, et al. Dynamic simulation and experimental validation of an open air receiver and a thermal energy storage system for solar thermal power plant[J]. Applied Energy, 2016, 178:281-293.

[137] Ni J, Zhao L, Zhang Z, et al. Dynamic performance investigation of organic Rankine cycle 
driven by solar energy under cloudy condition[J]. Energy, 2018, 147:122-141.

[138] Cole W J, Powell K M, Edgar T F. Optimization and advanced control of thermal energy storage systems[J]. Reviews in Chemical Engineering, 2012, 28(2-3):81-99.

[139] Khalilzadeh B V, Mahmoudimehr J. Modeling and optimization of the quasi-steady operation of a solar power plant equipped with thermal energy storage system. Modares Mechanical Engineering. 2016,15(10): 249-258.

[140] Arkar C, Šuklje T, Vidrih B, et al. Performance analysis of a solar air heating system with latent heat storage in a lightweight building[J]. Applied Thermal Engineering, 2016, 95:281-287. [141] Lane G A. Solar heat storage: latent heat materials[M]. Vol.1 Boca Raton, FL: CRC Press, Inc., 1983.

[142] Hachicha A A, Rodríguez I, Ghenai C. Thermo-hydraulic analysis and numerical simulation of a parabolic trough solar collector for direct steam generation[J]. Applied Energy, 2018, 214:152165.

[143] Calise F, D'Accadia M D, Macaluso A, et al. A novel solar-geothermal trigeneration system integrating water desalination: Design, dynamic simulation and economic assessment[J]. Energy, 2016, 115:1533-1547.

[144] Allouche Y, Varga S, Bouden C, et al. Dynamic simulation of an integrated solar-driven ejector based air conditioning system with PCM cold storage[J]. Applied Energy, 2017, 190:600-611.

[145] Fornarelli F, Camporeale S M, Fortunato B, et al. CFD analysis of melting process in a shelland-tube latent heat storage for concentrated solar power plants[J]. Applied Energy, 2016, 164:711722.

[146] Nithyanandam K, Pitchumani R, Mathur A. Analysis of a latent thermocline storage system with encapsulated phase change materials for concentrating solar power[J]. Applied Energy, 2014, 113: 1446-1460.

[147] Bie Y, Li M, Malekian R, et al. Effect of Phase Transition Temperature and Thermal Conductivity on the Performance of Latent Heat Storage System[J]. Applied Thermal Engineering, 2018, 135:218-227.

[148] G.Li, Energy and exergy performance assessments for latent heat thermal energy storage systems[J]. Renewable \& Sustainable Energy Reviews, 2015, 51:926-954. 